\title{
Nonlinear Optical Signal Processing for Tbit/s Ethernet Applications
}

\author{
L. K. Oxenløwe, M. Galili, H. C. Hansen Mulvad, H. Hu, J. L. Areal, E. Palushani, H. Ji, \\ A. T. Clausen, and P. Jeppesen
}

DTU Fotonik, Department of Photonics Engineering, Technical University of Denmark, Building 343, 2800 Kongens Lyngby, Denmark

Correspondence should be addressed to L. K. Oxenløwe, lkox@fotonik.dtu.dk

Received 31 May 2011; Accepted 12 July 2011

Academic Editor: Christophe Finot

Copyright () 2012 L. K. Oxenløwe et al. This is an open access article distributed under the Creative Commons Attribution License, which permits unrestricted use, distribution, and reproduction in any medium, provided the original work is properly cited.

\begin{abstract}
We review recent experimental demonstrations of Tbaud optical signal processing. In particular, we describe a successful $1.28 \mathrm{Tbit} / \mathrm{s}$ serial data generation based on single polarization $1.28 \mathrm{Tbaud}$ symbol rate pulses with binary data modulation (OOK) and subsequent all-optical demultiplexing. We also describe the first error-free $5.1 \mathrm{Tbit} / \mathrm{s}$ data generation and demodulation based on a single laser, where a 1.28 Tbaud symbol rate is used together with quaternary phase modulation (DQPSK) and polarization multiplexing. The $5.1 \mathrm{Tbit} / \mathrm{s}$ data signal is all-optically demultiplexed and demodulated by direct detection in a delayinterferometer-balanced detector-based receiver, yielding a BER less than $10^{-9}$. We also present subsystems making serial optical Tbit/s systems compatible with standard Ethernet data for data centre applications and present Tbit/s results using, for instance silicon nanowires.
\end{abstract}

\section{Introduction}

Historically, quadrupling the serial line rate has resulted in reducing the cost per bit by $40 \%$, mostly due to a reduction of terminal equipment and related power consumption [1]. For any given line rate, there will be trade-offs between the complexity of the line cards, the modulation format, the transmission reach, and the available technology at a given point in time. However, considering the historical facts, it is clear that there must be a potential for cost and power reductions when using higher serial line rates. It is merely a question of uncovering the right technological solutions. Today, electronic signal processing seems limited to about $120 \mathrm{Gbit} / \mathrm{s}$ [2], as stated by the high-speed electronics community itself, so it becomes relevant to explore optical signal processing and in particular in the context of high serial bit rates. Optical signal processing is well suited for serial data signals, since a single ultrafast optical switch can process the entire data content in one go. This may lead to a potential reduction in power consumption, as concluded in [3], where they state the following "photonic technologies may be well suited for processes such as the all-optical wavelength conversion and signal regeneration, where the number of signal processing devices is small." This is exactly the case for high serial line rates where a single device may perform the signal processing of the full data signal. Therefore, we believe it is relevant and interesting to conduct more research in the field of ultra-high-speed serial optical communications.

In the year 2000, the first demonstration of reaching Tbit/s data rates on a single wavelength channel was achieved [4] using 640 Gbaud polarization-multiplexing (pol-MUX) and simple OOK. Recently, it has become apparent that Tbit/s bit rates for Ethernet applications will be needed very soon [5] and that the overall necessary capacity per fiber will reach several tens of Tbit/s [6], while the need for power reductions is getting more and more evident, where the Internet today emits more than $2 \%$ of the global man-made $\mathrm{CO}_{2}$ emission. This has spurred on a regained focus on increasing the bit rates, both with a singlechannel perspective and with a spectral efficiency perspective using advanced modulation formats and latest advances in coherent receiver technology. A high single-channel bit rate has generally had the effect of cutting the overall systems 
cost, due to reduced network complexity, fewer components, and hence lower power consumption per bit. A high spectral efficiency may also help in power per bit savings, since the bandwidth is more efficiently used. Using OFDM has a high component count in the terminals but, on the other hand, is very resilient to transmission impairments and hence needs less inline equipment for, for example, regeneration. So the optimum path to energy-efficient high-bandwidth communication systems is still open, and all routes must be explored to ensure future sustainability.

Recent highlights of the endeavors to boost the bit rates to the Tbit/s regime include the record breaking $2.56 \mathrm{Tbit} / \mathrm{s}$ using DQPSK and pol-MUX on a 640 Gbaud RZ pulse rate [7] and a recent upgrade to 8 PSK on $640 \mathrm{Gbaud}$ with pol-MUX resulted in below FEC-limit $3.56 \mathrm{Tbit} / \mathrm{s}$ using coherent reception and $2.38 \mathrm{Tbit} / \mathrm{s}$ using $16 \mathrm{QAM}$ on 640 Gbaud without pol-MUX [8]. Including pol-MUX was also attempted but was not below the FEC limit, but could have resulted in $4.76 \mathrm{Tbit} / \mathrm{s}$. The combination of time division multiplexing and coherent receiver techniques has also been successfully studied by the Kikuchi group and recently led to a $1.28 \mathrm{Tbit} / \mathrm{s}$ based on 16 QAM on a $160 \mathrm{Gbaud}$ pol-MUX OTDM pulse train [9]. Using coherent OFDM has also recently been demonstrated to reach $1 \mathrm{Tbit} / \mathrm{s}$ [10] and even 1.2 Tbit/s [11]. The simple OOK purely serial format has the advantage of having a low component count with simple line cards, as well as being the simplest format with several well-established suggestions for all-optical regeneration, which may also aid in driving the power consumption down. Successful demonstrations of regenerating the phase have also been obtained recently [12], and this may also be applied to OTDM phase-modulated data. Drawbacks of binary OTDM are the relatively low spectral efficiency and the severe challenges with respect to long-haul transmission. Until very recently, the baud rate had been limited to 640 Gbaud, but a new record of $1.28 \mathrm{Tbit} / \mathrm{s}$ was recently demonstrated [13] using only optical time division multiplexing (OTDM) from $10 \mathrm{Gbit} / \mathrm{s}$ and remaining in one single polarization, that is, a purely serial 1.28 Tbaud symbol rate.

In this paper, we describe recent progress on $1.28 \mathrm{Tbit} / \mathrm{s}$ data generation and demultiplexing and discuss opportunities and limitations of this technology. Using $300 \mathrm{fs}$ wide (FWHM) 1.28 Tbaud symbols for more advanced modulation formats has also been demonstrated with a world-first error-free 5.1 Tbit/s data generation and demodulation [14]. DQPSK and polarization multiplexing were used, and the details of this will also be presented here.

\section{Experimental Demonstrations: Background}

A schematic of the experimental setup used for the demonstrations described here is shown in Figure 1. An erbium glass oscillator pulse generating laser (ERGO) supplies a $10 \mathrm{GHz}$ optical pulse train at $1557 \mathrm{~nm}$ having a pulse width of 1.3 ps. A Mach-Zender modulator (MOD) is used to encode a data sequence $\left(2^{7}-1\right.$ PRBS) on the pulse train. The 10 Gbit/s modulated pulse train is compressed down to $350 \mathrm{fs}$ in a highly nonlinear fiber (HNLF) SPM-based chirp unit followed by linear dispersion and subsequently multiplexed to $160-320-640-1280 \mathrm{Gbit} / \mathrm{s}$ in a passive fiber delay PRBS and polarization-maintaining multiplexer (MUX). The multiplexed data is then subjected to various experiments.

Several interesting functionalities have already been demonstrated at $640 \mathrm{Gbit} / \mathrm{s}$ and show promise for higher bit rates. This goes for transmission and clock recovery, wavelength conversion, and add/drop multiplexing, all of which have been demonstrated at $640 \mathrm{Gbit} / \mathrm{s}$ in our testbed [15-20]. These functionalities are likely to be possible to perform at $1.28 \mathrm{Tbit} / \mathrm{s}$, as the physical properties involved in the signal processing are fast enough. For the clock recovery scheme described in $[15,16]$, a periodically poled Lithium Niobate (PPLN) device was used as an all-optical mixer, and it was fast enough to resolve the $640 \mathrm{Gbit} / \mathrm{s}$ data signal. In [21] is described how a similar PPLN device is used to compress an optical pulse to less than $100 \mathrm{fs}$, revealing the great speed potential of the $\chi^{(2)}$ process, which takes place on an fs timescale. So these devices have great potential for Tbit/s applications. The HNLF used for wavelength conversion and add/drop multiplexing in [1720 ] are the same types as used for the $1.28 \mathrm{Tbit} / \mathrm{s}$ experiment, so they have already proven themselves able to operate at Tbit/s speeds. An alternative to HNLF is the very nonlinear chalcogenide waveguides. In [22], we showed that such a device could be used to demultiplex a $640 \mathrm{Gbit} / \mathrm{s}$ data signal, and as with the HNLF and the PPLN, the active effect used for the optical signal processing is ultrafast, and the only speed limitation lies in the design of the dispersion (this goes for all the devices). Recently, in [23], it was shown that these waveguides indeed have a $\mathrm{THz}$ response with a modulation bandwidth on the order of $2.5 \mathrm{THz}$. This means that this technology would also lend itself favorably to Tbit/s serial communication systems. Very recently, it was thus demonstrated that $1.28 \mathrm{Tbit} / \mathrm{s}$ demultiplexing is indeed possible with such a chalcogenide device [24].

\section{1.28 Tbit/s OOk Serial Data Generation}

A detailed set-up drawing of the $1.28 \mathrm{Tbit} / \mathrm{s}$ experiment is shown in Figure 2. In this back-to-back set-up, only a single pulse source is used. This feeds both the data generation part and the control pulse part in the demultiplexer. The pulses are split in two parts after an SPMbased wavelength conversion unit. A supercontinuum is generated in $400 \mathrm{~m}$ of dispersion-flattened HNLF (DFHNLF1). DF-HNLF1 has dispersion $D=-0.45 \mathrm{ps} / \mathrm{nm} \mathrm{km}$ and slope $S=0.006 \mathrm{ps} / \mathrm{nm}^{2} \mathrm{~km}$ at $1550 \mathrm{~nm}$, nonlinear coefficient $\gamma=10.5 \mathrm{~W}^{-1} \mathrm{~km}^{-1}$ ). It is very important that the HNLF is slightly negative in dispersion and has a very flat dispersion profile, as this gives the best supercontinuumin this case a $70 \mathrm{~nm}$ wide spectrum, see Figure 3. The top branch is filtered through a $9 \mathrm{~nm}$ wide filter, which is offset by $15 \mathrm{~nm}$ from the original pulse source wavelength. This has two effects: firstly, a Mamyshev regeneration takes place suppressing the inevitable pulse pedestals from the external cavity mode-locked laser, and secondly, a linear chirp is obtained across the pulse, and by carefully measuring out the path to the demultiplexer, the resulting dispersion is such that a transform-limited short pulse of width $400 \mathrm{fs}$ 

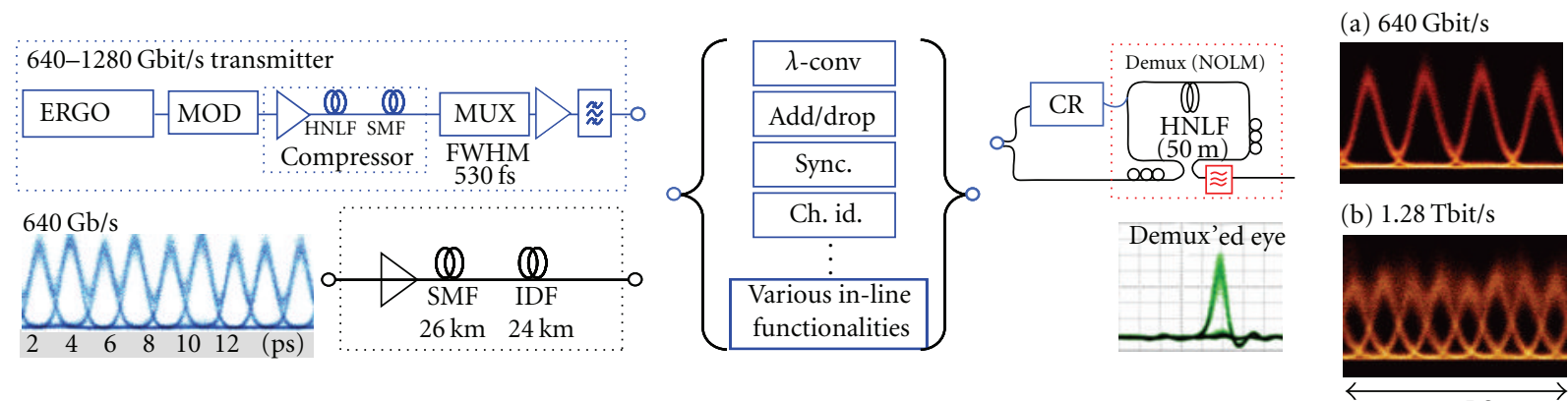

6.25 PS

FIGURE 1: Schematic of the DTU OTDM test bed for generating 640-1280 Gbit/s data. Insets: (a) 640 Gbit/s eye diagram, (b) 1.28 Tbit/s eye diagram.

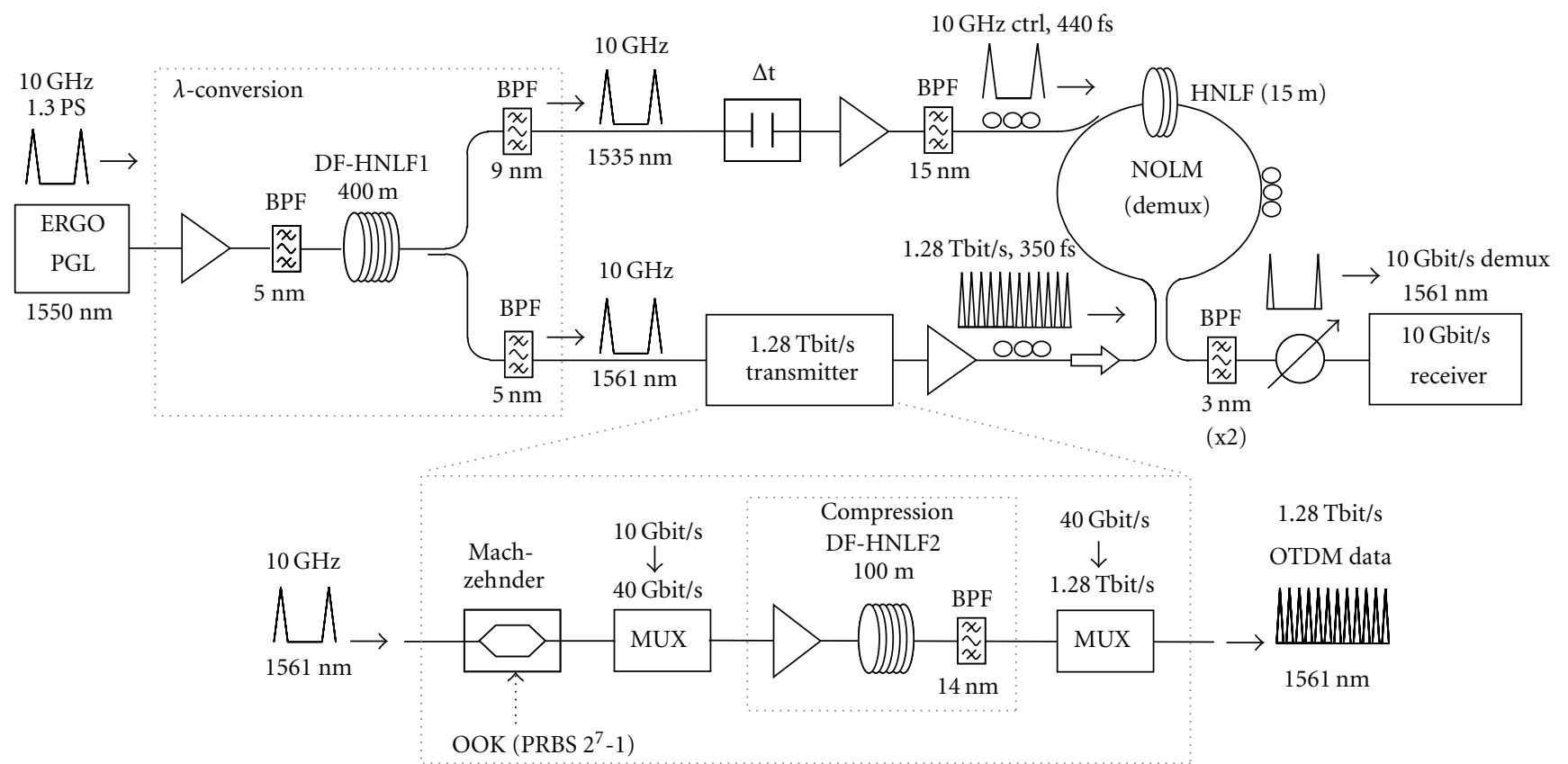

FIGURE 2: Experimental set-up for a back-to-back demonstration of $1.28 \mathrm{Tbit} / \mathrm{s}$ serial data generation and demultiplexing.

FWHM is obtained at the input to the HNLF in the nonlinear optical loop mirror (NOLM). The lower branch is also offset filtered by $11 \mathrm{~nm}$ in a $5 \mathrm{~nm}$ wide filter to separate it effectively from the original wavelength. These pulses, now at $1561 \mathrm{~nm}$, are data modulated at $10 \mathrm{Gbit} / \mathrm{s}$ with a $2^{7}-1$ PRBS OOK data signal. The PRBS length is merely chosen for convenience, as the multiplexer is designed to preserve this PRBS word. Longer word lengths become impractical for this type of lab-solution MUX. For all experiments mentioned here, the PRBS length does not matter, since only truly ultrafast optical switching effects are used, which effectively alleviates any potential patterning effects. Changing the PRBS length would thus only serve to characterize the $10 \mathrm{Gbit} / \mathrm{s}$ photodetector and receiver. This has of course been done, with no difference between a $2^{7}-1$ and a $2^{31}$ 1 PRBS word. Following the data modulation, the data is multiplexed to $40 \mathrm{Gbit} / \mathrm{s}$, and then it is further compressed in a second SPM-based compression stage (DF-HNLF2: $D=$ $\left.-1.7 \mathrm{ps} /(\mathrm{nm} \mathrm{km}), S=0.004 \mathrm{ps} /\left(\mathrm{nm}^{2} \mathrm{~km}\right) 1560 \mathrm{~nm}\right)$ with a $14 \mathrm{~nm}$ bandpass filter. The data pulses are then sent through the remainder of the multiplexer, reaching $1.28 \mathrm{Tbit} / \mathrm{s}$ and being compressed down to about $350 \mathrm{fs}$.

The $1.28 \mathrm{Tbit} / \mathrm{s}$ data is subsequently demultiplexed in the NOLM, which contains a $15 \mathrm{~m}$ short HNLF with a zero dispersion at $1545 \mathrm{~nm}$ and a slope of $0.015 \mathrm{ps} / \mathrm{nm}^{2} \mathrm{~km}$. With a short HNLF and a zero dispersion wavelength in between the control and data, walk-off is reduced to a negligible level (less than $50 \mathrm{fs}$ ). Furthermore, the short HNLF helps to enhance overall stability by reducing the amount of second-order PMD. The demultiplexed data channels are characterized in terms of bit error rate (BER) performance.

The heart of an ultra-high-speed serial data system is the short-pulse generation. Figure 3 shows details of the pulse compression. The optimally compressed pulses are as short as $196 \mathrm{fs}$ FWHM, which is adequate for $1.28 \mathrm{Tbit} / \mathrm{s}$ signals. Please note that there is a small background offset in the 


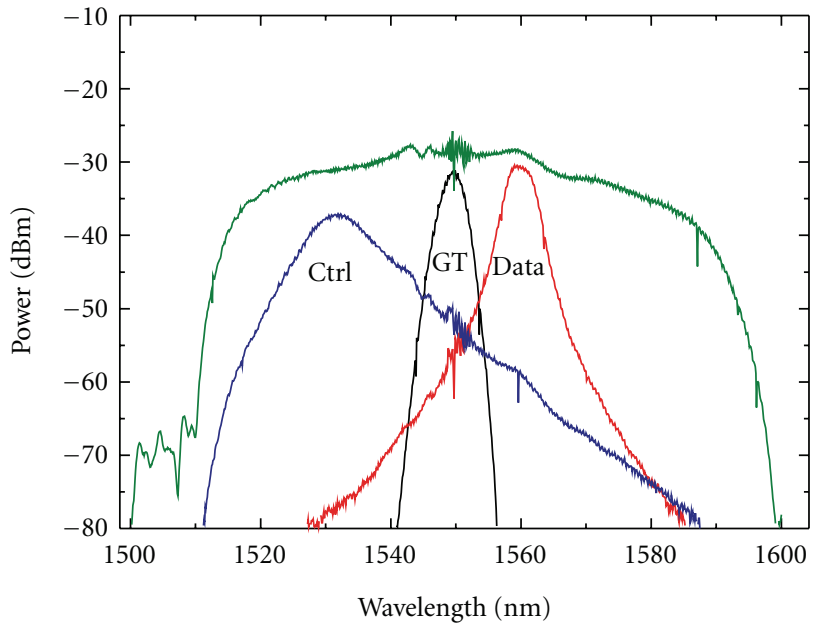

(a)

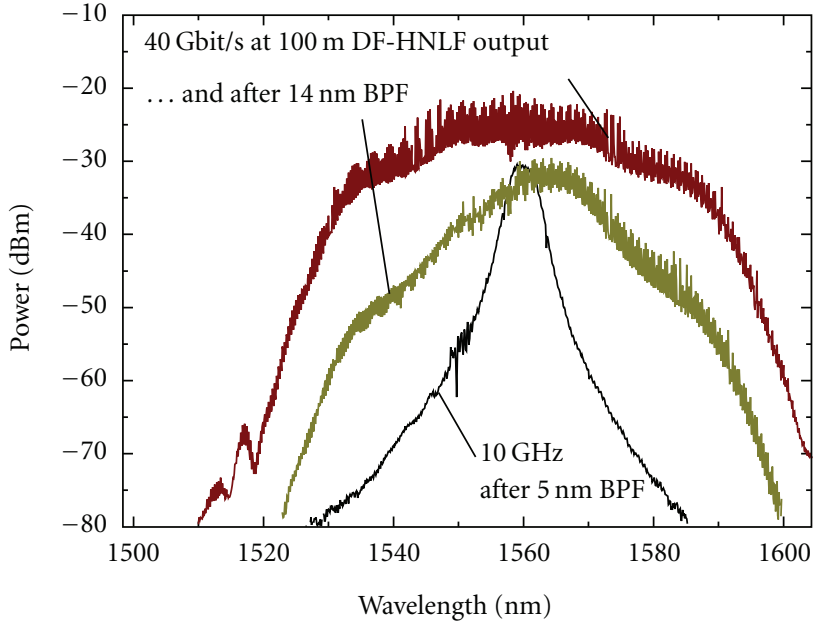

(b)

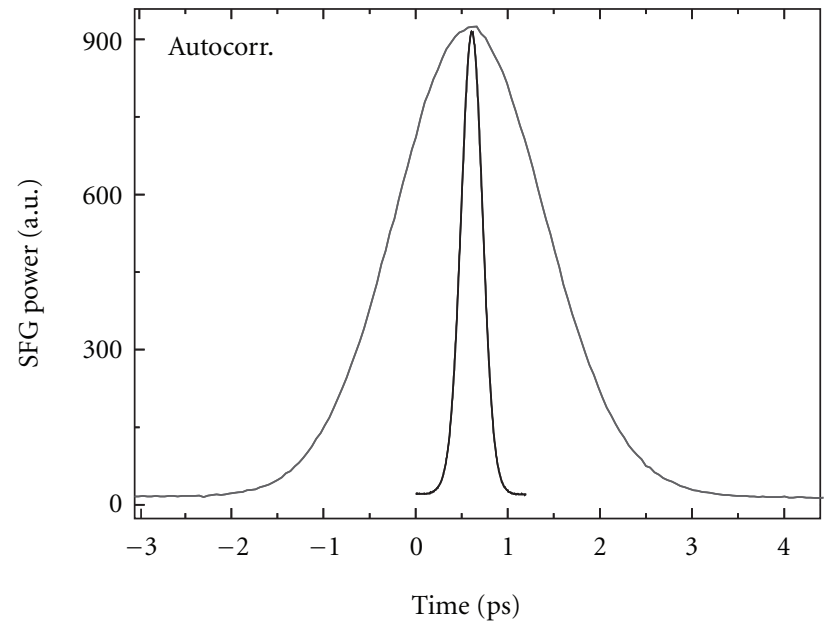

Gaussian pulse FWHM

Input $1.36 \mathrm{ps}$

Output 196 fs

(c)

FIGURE 3: Pulse compression for 1.28 Tbit/s pulses. (a) Spectra at the input and output of DF-HNLF1. The "GT" trace is the input to the DF-HNLF1 creating the $70 \mathrm{~nm}$ wide supercontinuum trace. From this supercontinuum, a control and data spectrum is carved out. (b) The data spectra at DF-HNLF2 showing the input (data output from DF-HNLF2), the resulting generated supercontinuum in DF-HNLF2 and the final filtered $(14 \mathrm{~nm}$ ) compressed output. (c) Autocorrelation traces of the input data pulse and the optimally compressed pulse revealing a 196 fs FWHM pulse.

autocorrelation traces, caused partly by ASE noise. In practice, the multiplexer stages and other parts of the full system result in a small broadening of this, so the data pulses end up being around $350 \mathrm{fs}$ wide FWHM. This is still adequate for $1.28 \mathrm{Tbit} / \mathrm{s}$, as will be seen below.

The compressed pulses are multiplexed, and the resultant eye diagrams, as measured on an optical sampling oscilloscope (OSO) with a 1 ps timing resolution, are shown in Figure 4. The resolution of the OSO is obviously not sufficient to resolve the $350 \mathrm{fs}$ pulses, but the OTDM time slot for a $1.28 \mathrm{Tbit} / \mathrm{s}$ data signal is about $750 \mathrm{fs}$, which can just be discerned by the OSO. Therefore, the OSO can show open-eye diagrams at $1.28 \mathrm{Tbit} / \mathrm{s}$. But the real pulse widths are much shorter than it seems here. Figure 4 also shows a $640 \mathrm{Gbit} / \mathrm{s}$ eye diagram, and as can be seen on that there is ample room between the data pulses for an extra time slot.

The generated $1.28 \mathrm{Tbit} / \mathrm{s}$ data signal is subsequently sent to the NOLM demultiplexer. It is very important that there is as low a spectral overlap as possible between the control and data in the NOLM, which is challenging if the system is constrained to remain in the C-band and the spectra are about $15 \mathrm{~nm}$ wide each. However, as seen in Figure 5, there is a small overlap, but the effect of this can be minimized by keeping the detrimental SPM broadening at a minimum 


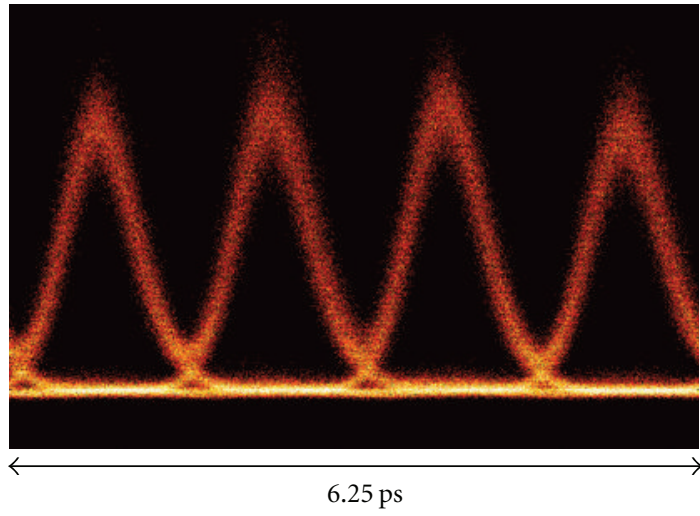

(a) $640 \mathrm{Gbit} / \mathrm{s}$

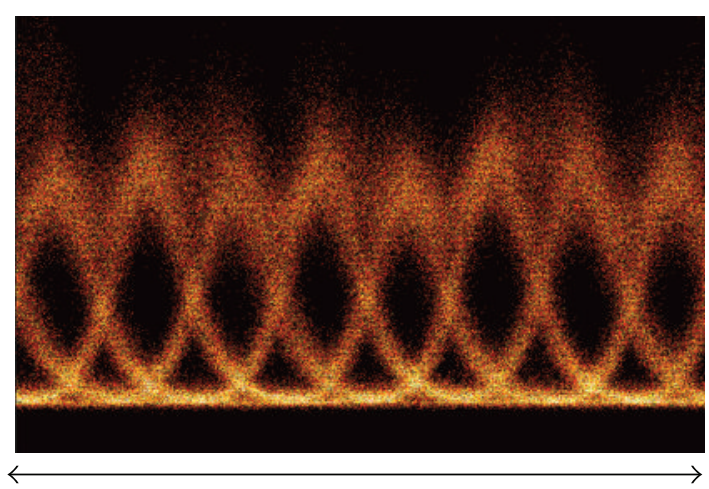

(b) $1.28 \mathrm{Tbit} / \mathrm{s}$

Figure 4: $1.28 \mathrm{Tbit} / \mathrm{s}$ data generation. Eye diagrams measured by an optical sampling oscilloscope with limited timing resolution to 1 ps. (a) $640 \mathrm{Gbit} / \mathrm{s}$ eye diagram. (b) $1.28 \mathrm{Tbit} / \mathrm{s}$ eye diagram. Note that the real pulses are only about $350 \mathrm{fs}$ wide.

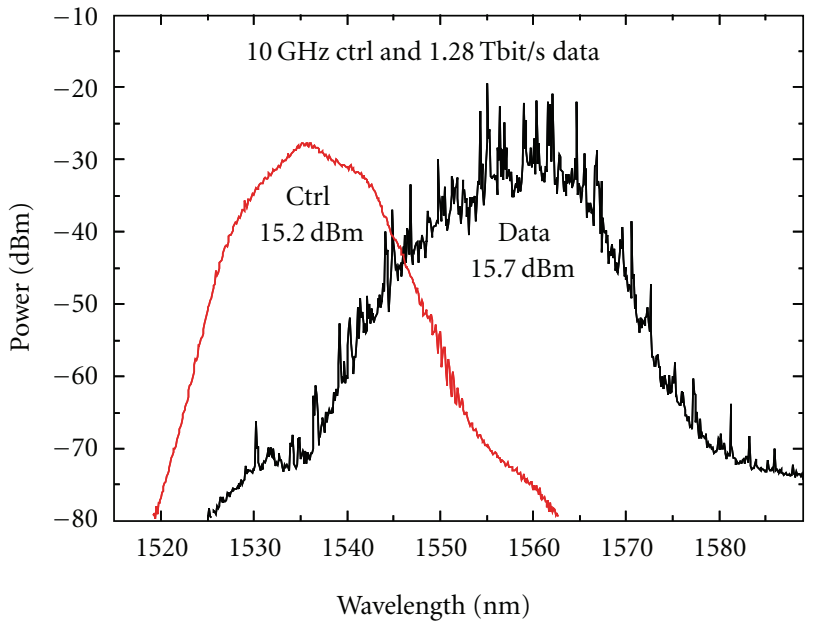

Figure 5: Spectral overlap of control and data pulses in the NOLM.

by careful adjustment of the polarization. This is enabled because a short HNLF is used in the NOLM, and by using a moderate control power to get a good SPM/XPM balance (in this case $\sim 0.7 \pi \mathrm{XPM})$. The control power used is $15.2 \mathrm{dBm}$, and the data signal input power is $15.7 \mathrm{dBm}$.

The demultiplexing results are shown in Figure 6. $1.28 \mathrm{Tbit} / \mathrm{s}$ demultiplexing is seen to be error-free. For comparison with the performance at $640 \mathrm{Gbit} / \mathrm{s}$, the last multiplexer stage is shut, yielding a $640 \mathrm{Gbit} / \mathrm{s}$ signal. Tracking the very same channel (channel 0 ) while turning the final multiplexer stage on again ensures that it is the same channel that is measured on. This channel is shown with a triangular symbol in Figure 6 and reveals a modest power penalty of about $2.4 \mathrm{~dB}$. To ensure that the final multiplexing is properly adjusted, the BER curves for the neighboring channels (ch.0-1) and (ch.0+1) are also shown, and they have almost identical BER performances with the same sensitivity of $-33.3 \mathrm{dBm}$. There is however an indication of an error-floor below BER $10^{-10}$ for the $1.28 \mathrm{Tbit} / \mathrm{s}$ data. The demultiplexed eye diagrams in Figure 6 are all clear and open, with a tendency of more noise appearing for higher bit rates. This is not surprising, as the pulse tail overlap will increase for higher bit rates. The $10 \mathrm{Gbit} / \mathrm{s}$ back-toback (b2b) baseline is measured straight out of the data modulator, that is, before the pulse compression and without being sent through the NOLM demultiplexer. This means that the pulse shape is different from the multiplexed cases, which results in different BER slopes.

In order to validate the integrity of the full $1.28 \mathrm{Tbit} / \mathrm{s}$ data signal, all 128 channels are characterized. Figure 7 shows the BER results for all 128 demultiplexed OTDM tributaries of the $1.28 \mathrm{Tbit} / \mathrm{s}$ data signal.

The integrity of the $1.28 \mathrm{Tbit} / \mathrm{s}$ data signal is tested by verifying that error-free performance can be obtained for all channels after demultiplexing. This test is performed by lowering the attenuation before the receiver sufficiently to obtain a BER $<10^{-9}$ for each individual channel. Note that the error detector decision level is not adjusted for minimum BER, but only until a BER $<10^{-9}$ is detected. For all 128 channels, a BER $<10^{-9}$ can be obtained, confirming the integrity of the $1.28 \mathrm{Tbit} / \mathrm{s}$ data signal. The variation in BER performance is attributed to the MUX, in which the channels propagate through different lengths of SMF and therefore acquire slightly different pulse widths at the MUX output. Furthermore, small misalignments of the temporal delays in the MUX stages are also expected to contribute to the aforementioned variations.

3.1. Transmission Performance. It is well known that transmission of narrow pulses is a challenge, due to dispersion and PMD. It is also clear that a $1.28 \mathrm{Tbit} / \mathrm{s}$ data signal is more interesting if it can be transmitted over fiber. In order to characterize this, we investigated the transmission performance over an $80 \mathrm{~km}$ standard single mode (SMF) fiber span only compensated by $11 \mathrm{~km}$ dispersion compensating fiber (DCF) and a $1 \mathrm{~km}$ dispersion-shifted fiber (DSF) for additional slope compensation. The fibers are kindly provided by OFS Fitel Denmark Aps. The PMD is mitigated by launching the data signal into a principal state of polarization, and monitoring the polarization state at the output of the fiber. 

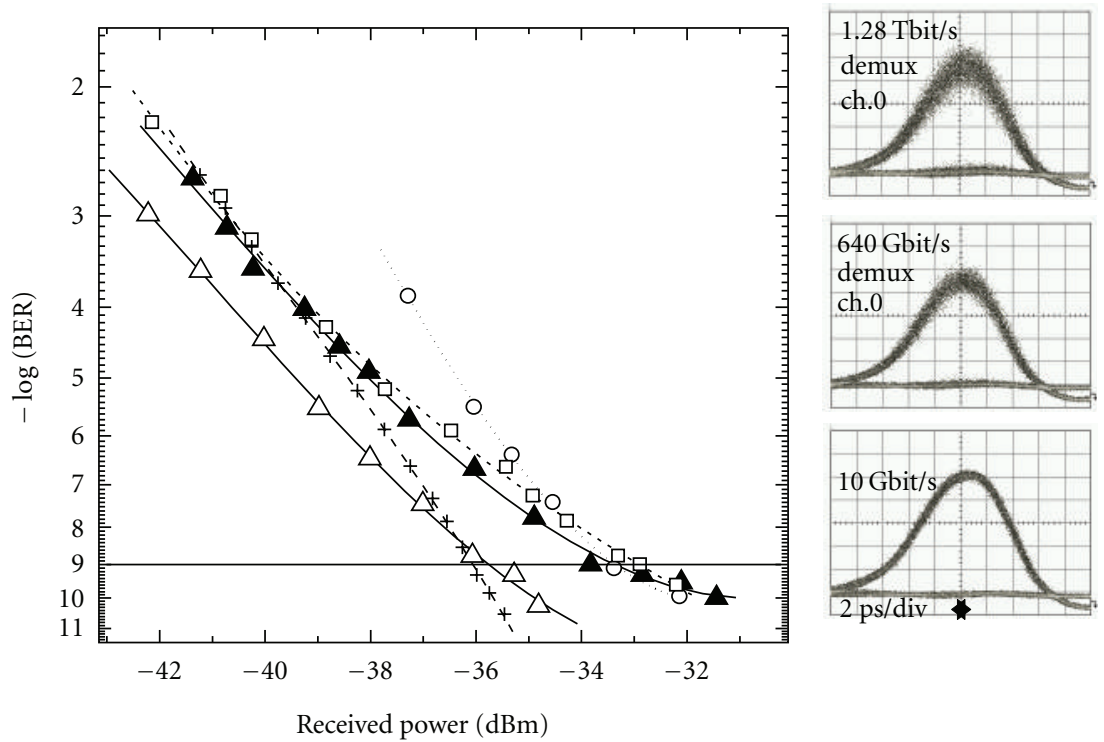

$$
\begin{aligned}
& \text { - } 1.28 \mathrm{Tbit} / \mathrm{s} \text { demux (ch.0) } \\
& \triangle 640 \mathrm{Gbit} / \mathrm{s} \text { demux (ch.0) } \\
& \text { ㅁ } 1.28 \mathrm{Tbit} / \mathrm{s} \text { demux (ch.0+1) } \\
& \begin{array}{ll}
\triangle & 640 \mathrm{Gbit} / \mathrm{s} \text { demux (ch.0) } \\
\text { ○ } & 1.28 \mathrm{Tbit} / \mathrm{s} \text { demux (ch.0-1) }
\end{array}
\end{aligned}
$$

FIGURE 6: BER results for $1.28 \mathrm{Tbit} / \mathrm{s}$ demultiplexing. Left: BER performance showing error-free $\left(\right.$ BER $\left.<10^{-9}\right)$ performance. Right: demultiplexed eye diagrams for $1.28 \mathrm{Tbit} / \mathrm{s}$ (top), $640 \mathrm{Gbit} / \mathrm{s}$ (middle), and the $10 \mathrm{Gbit} / \mathrm{s}$ back to back (bottom).

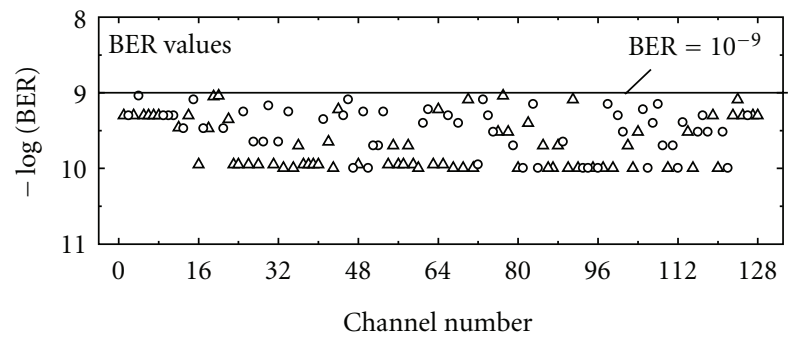

FIGURE 7: BER values for all 128 tributaries. All channels are errorfree $\left(\mathrm{BER}<10^{-9}\right)$ corroborating the open eyes from Figure 1, taken from [13].

Figure 8 shows a schematic of the transmission set-up. A $10 \mathrm{GHz}$ clock signal is transmitted along with the data signal to synchronize the receiver. The $1.28 \mathrm{Tbit} / \mathrm{s}$ transmitter and receiver are the same as described above, except for the control pulse for the NOLM, which is derived from a second ERGO laser driven by the o/e-converted transmitted clock signal and compressed in a separate pulse compressor similar to the one described above.

Figure 9 shows the residual dispersion of the fiber span with a residual disp. within $\pm 50 \mathrm{fs} / \mathrm{nm}$ over nearly $20 \mathrm{~nm}$ (as specified by manufacturer). The data pulses for $1.28 \mathrm{Tbit} / \mathrm{s}$ (at $\sim 1556 \mathrm{~nm}$ ) can then be transmitted with negligible broadening, see Figure 9(b).

The preliminary experiments show promising results for transmission over this fiber span. The pulse broadening is kept at a minimum, with a broadening from $375 \mathrm{fs}$ to
$400 \mathrm{fs}$ FWHM. In terms of BER performance, a BER of $10^{-6}$ is obtained. Interestingly enough, it is not the dispersion that causes the biggest problems in this set-up, but rather the available OSNR. The spectrum of the data is so wide that it has energy distributed all over the C-band, and the competition in the EDFAs with the transmitted clock signal made it difficult to find a good balance-either the clock OSNR was good with low resulting phase noise and timing jitter, or the data signal OSNR was good. But a perfect balance between the two was not achieved in this preliminary experiment.

Very recently, it was demonstrated that it is really possible to transmit the Tbaud pulses over significant fibre lengths [25]. Figure 10 shows the principle and results for transmitting a $1.28 \mathrm{Tbit} / \mathrm{s}$ differential phase-shift-keying (DPSK) data signal over $50 \mathrm{~km}$ superlarge area transmission fibre with inverse dispersion fibre for dispersion compensation (SLA-IDF) using a transmitted clock. The result is errorfree, and there is thus no fundamental dispersion issues limiting the transmission of these sub-ps pulses, as long as the dispersion is carefully compensated. Here, only standard IDF was used with small pieces of DCF and DSF to finetune the dispersion. The $50 \mathrm{~km}$ transmission link is composed of a $25 \mathrm{~km} S L A\left(D=20 \mathrm{ps} / \mathrm{nm} / \mathrm{km}, S=0.06 \mathrm{ps} / \mathrm{nm}^{2} / \mathrm{km}\right.$ and $\left.P M D=0.04 \mathrm{ps} / \mathrm{km}^{1 / 2}\right)$ and a $25 \mathrm{~km} \operatorname{IDF}(D=-20 \mathrm{ps} / \mathrm{nm} / \mathrm{km}$, $S=-0.06 \mathrm{ps} / \mathrm{nm}^{2} / \mathrm{km}$, and PMD $\left.=0.02 \mathrm{ps} / \mathrm{km}^{1 / 2}\right)$.

In a real system, dispersion will vary as a function of temperature, and therefore adaptive dispersion compensation techniques will be necessary. There are good suggestions available today such as, for example, the optical fourier transform (OFT) technique [26], or a spectral pulse shaper (SPS) with 


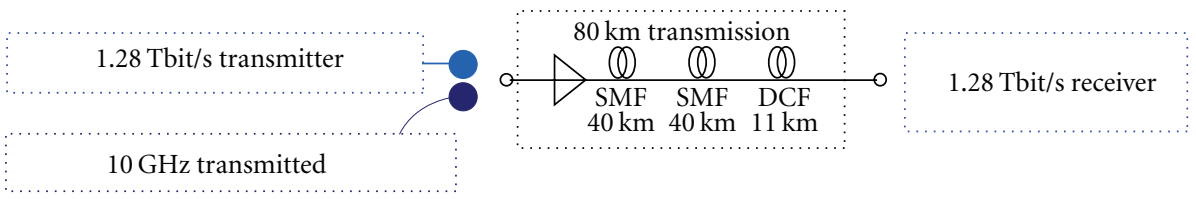

FIgure 8: Transmission set-up. A transmitted $10 \mathrm{GHz}$ clock signal are used for synchronizing the receiver. $80 \mathrm{~km}$ SMF and $11 \mathrm{~km}$ DCF is used.

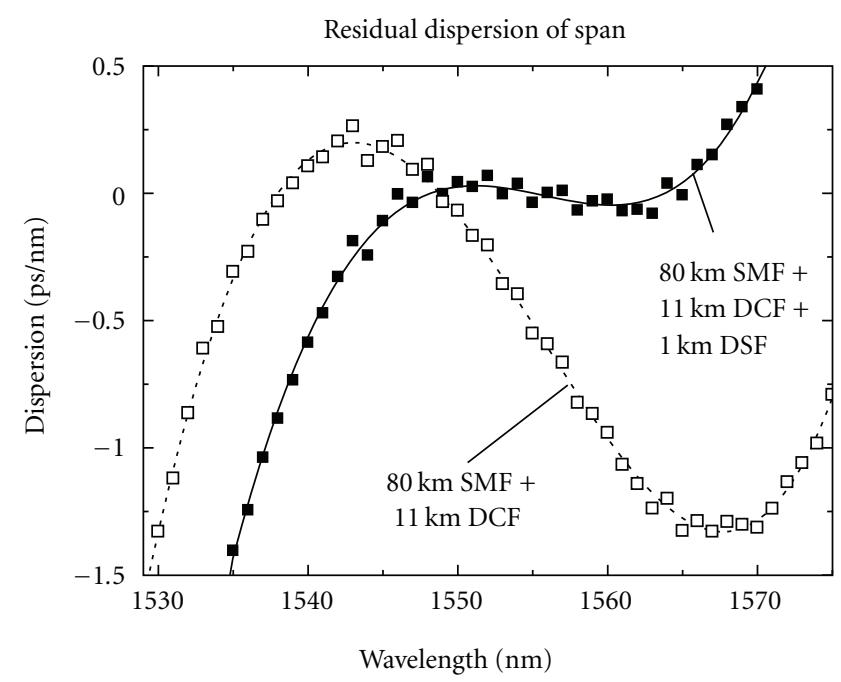

(a)

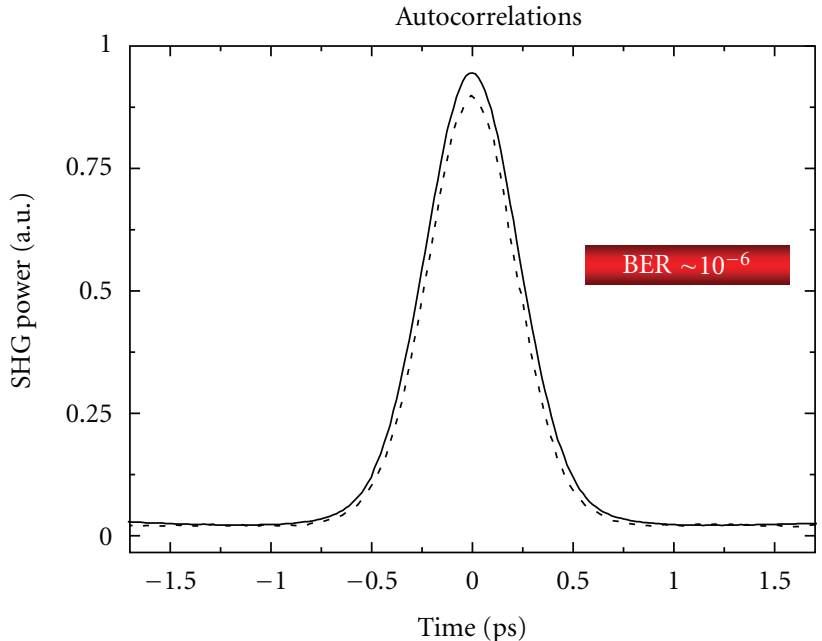

Before span:

... fwhm $531 \mathrm{fs}$

$(\sim 375$ fs pulse $)$
After span:

— fwhm $562 \mathrm{fs}$ ( $\sim 400$ fs pulse)

(b)

Figure 9: Preliminary transmission results. The stated "fwhm" pulse widths are autocorrelation measurements. The deconvoluted FWHM pulse widths are in brackets $(375 / 400 \mathrm{fs})$.
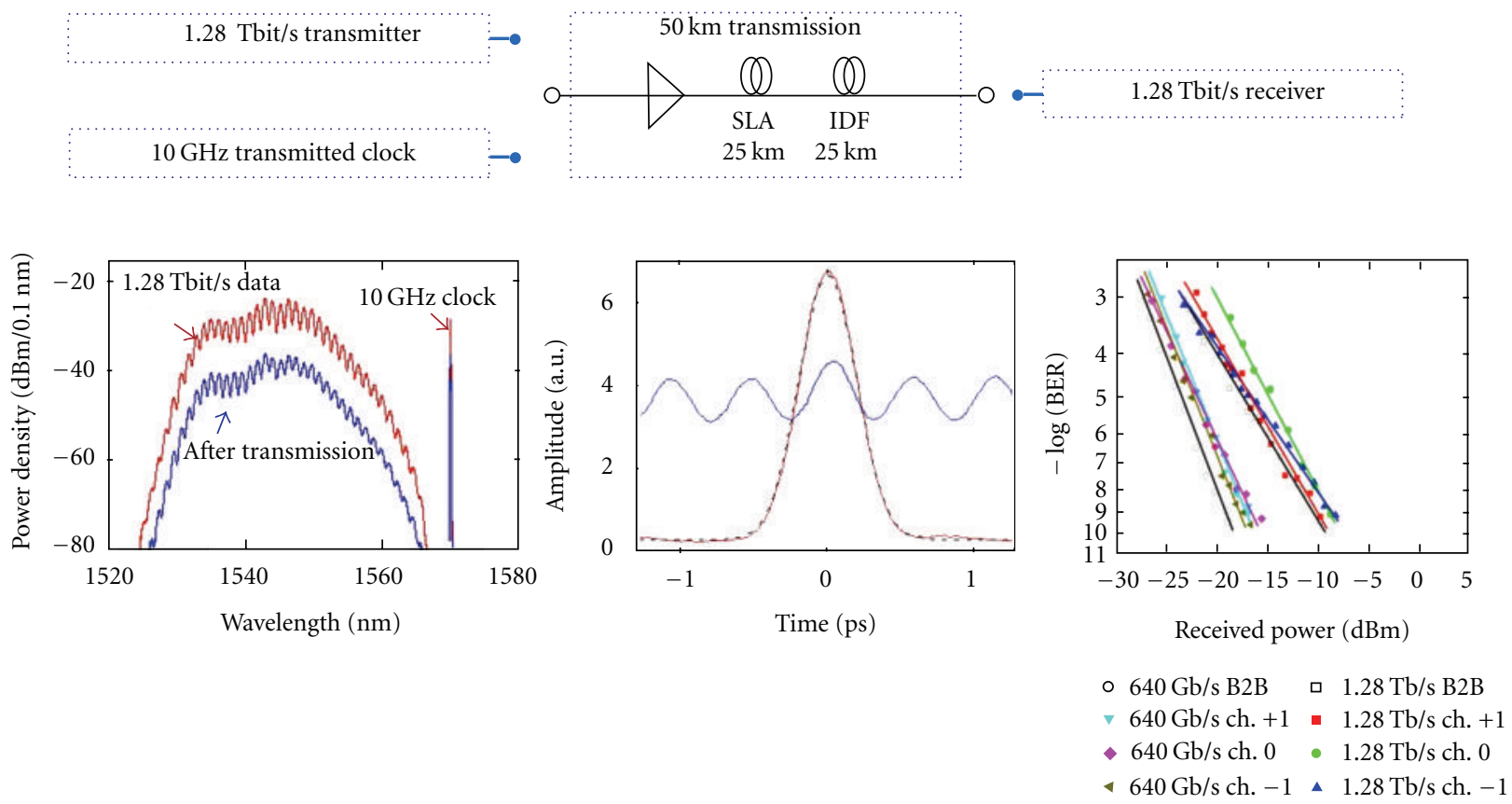

FIGURE 10: 1.28 Tbit/s DPSK transmission over $50 \mathrm{~km}$ SLA-IDF using an L-band $10 \mathrm{GHz}$ transmitted clock [25]. 


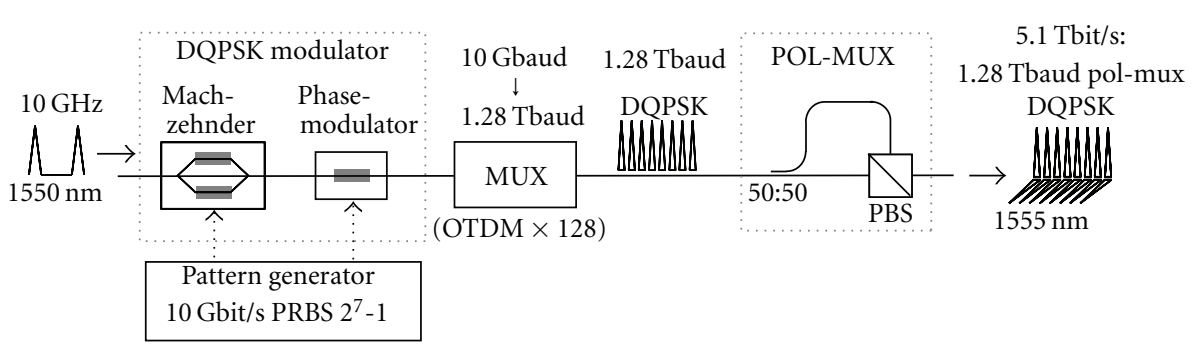

Figure 11: 5.1 Tbit/s data generation set-up.

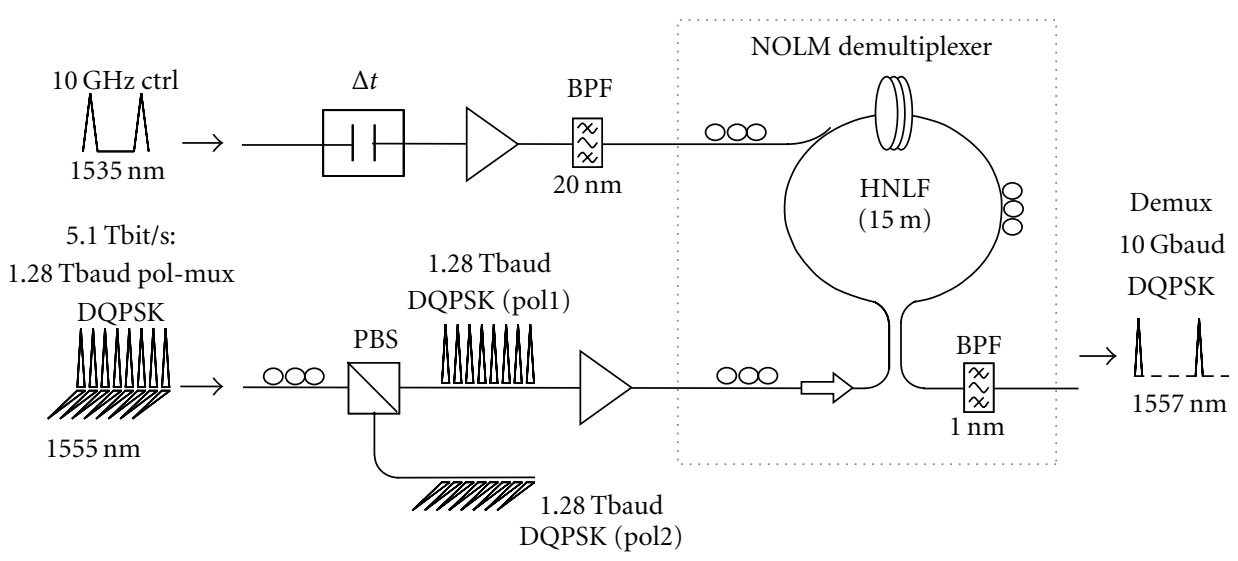

FIGURE 12: 5.1 Tbit/s demultiplexer receiver with a pol-DEMUX (PBS) and an NOLM DEMUX, yielding 10 Gbaud symbols.

adjustable phase [27]. For PMD, a liquid crystal modulator scheme has been demonstrated to compensate for all-order $P M D$ on subpicosecond pulses in a potentially adaptive setup [28]. To conclude on this section, it is possible to generate an error-free $1.28 \mathrm{Tbit} / \mathrm{s}$ purely serial data signal, and even transmission is demonstrated, when careful compensation of the dispersion is applied.

\section{5.1 Tbit/s Dqpsk Pol-MUX Data Generation}

In this section, we describe the upgrade from $1.28 \mathrm{Tbit} / \mathrm{s}$ to $5.1 \mathrm{Tbit} / \mathrm{s}$. The main idea behind this experiment is to use the generated record high symbol rate of 1.28 Tbaud, as described above. Each pulse is now compressed to about $400 \mathrm{fs}$ first, and subsequently phase modulated rather than intensity modulated. A differential quaternary phase-shift-keying (DQPSK) data signal is encoded onto the pulses in two steps. First, a push-pull Mach-Zehnder modulator is used to add a $2^{7}-1$ PRBS DPSK data signal to the $10 \mathrm{GHz}$ compressed pulses.

The data generation is schematically represented in Figure 11. The second level of data to generate the DQPSK signal is added by a $\mathrm{LiNbO}_{3}$ phase modulator. This modulator is also adding a decorrelated $2^{7}-1$ PRBS data signal with a $\pi / 2$ offset compared to the DPSK signal, thus assuring an even distribution of the quaternary phase levels. Note that the aggregated DQPSK data signal is not a preserved PRBS sequence. However, as mentioned above, the specific data sequence is not important here, as a pattern-dependentfree receiver is used. The $20 \mathrm{Gbit} / \mathrm{s}$ (10 Gbaud) DQPSK data signal is then multiplexed in the same split-and-delay multiplexer as described above up to 1.28 Tbaud, that is, $2.56 \mathrm{Tbit} / \mathrm{s}$. Then an additional polarization multiplexing is imposed on the data signal, by splitting the signal in two in a 3-dB coupler, and then aligning the polarization to match the inputs to a polarization beam splitter (PBS). The PBS combines the two orthogonally polarized 1.28 Tbaud data copies in a $5.1 \mathrm{Tbit} / \mathrm{s}$ DQPSK pol-multiplexed data signal.

The $5.1 \mathrm{Tbit} / \mathrm{s}$ data signal is then sent to the same NOLM demultiplexer as described above, see Figure 12.

Before entering the NOLM, the $5.1 \mathrm{Tbit} / \mathrm{s}$ data signal is split in its two polarization states by a second PBS. Each polarization state is characterized separately, one after the other. The control pulse for the NOLM is derived the same way as above.

The demultiplexed 10 Gbaud DQPSK data signal is further demodulated in a standard 10 Gbaud DQPSK receiver, see Figure 13. A delay interferometer (DLI) with a phase tuner is used to choose the I or the Q component, and the DLI outputs are detected in a balanced photodetector and evaluated in a BER counter.

Figure 14 shows an autocorrelation trace of the 1.28 Tbaud data signal together with the $10 \mathrm{GHz}$ control pulse. The data pulses are about $410 \mathrm{fs}$ wide (FWHM) in this case, and the control pulse is around $440 \mathrm{fs}$ wide. The data signal is well equalized and correctly separated. The BER results are shown in Figure 15 for a 640 Gbaud 2.56 Tbit/s signal and a $1.28 \mathrm{Tbaud} 5.1 \mathrm{Tbit} / \mathrm{s}$ signal. In both cases, error-free performance is achieved.

At 1.28 Tbit/s ( $640 \mathrm{Gbaud}$, no pol-MUX), the $10 \mathrm{Gbit} / \mathrm{s}$ I/Q components have sensitivities of $-35.3 \mathrm{dBm}$ and $-34.8 \mathrm{dBm}$. There is a penalty of less than $3 \mathrm{~dB}$ compared 


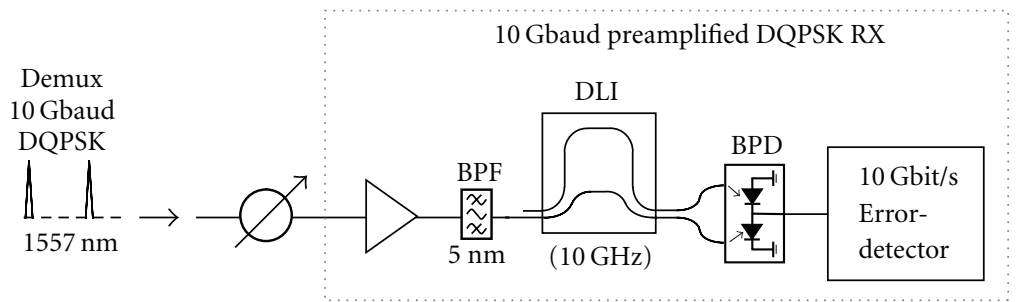

FIgURE 13: 5.1 Tbit/s demodulator receiver with a preamplifier, a delay interferometer, and a balanced detector.

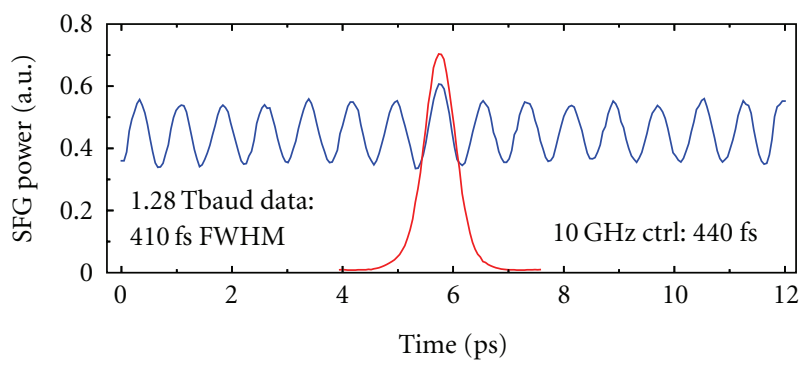

FIGURE 14: 1.28 Tbaud data pulses with DQPSK modulation.

to the 10 Gbaud reference I/Q sensitivity of $-37.5 \mathrm{dBm}$ (obtained by injecting the DQPSK modulator output directly into the DQPSK receiver). When adding pol-MUX to reach $2.56 \mathrm{Tbit} / \mathrm{s}$, the penalty is only increased by $0.5 \mathrm{~dB}$. The symbol rate is subsequently doubled to 1.28 Tbaud, yielding a total bit rate of 5.1 Tbit/s. Figure 14 (bottom) shows the BER results for the case, when using pol-MUX, showing the I/Q components of a demultiplexed 10 Gbaud channel, and the inset (top right) shows the demodulated eye diagram for this case. The eye is clearly open, and the BER confirms errorfree performance of both polarizations and both the I and Q components. BER values $<10^{-9}$ are detected for all measured curves, hence demonstrating that error-free performance can be obtained for the 5.1 Tbit/s data signal. There is however an error floor below $10^{-9}$ and a penalty of $\sim 7-10 \mathrm{~dB}$ relative to the 10 Gbaud DQPSK reference sensitivity. This is primarily attributed to a slightly too large data pulse FWHM of $\sim 410 \mathrm{fs}$ compared to the 1.28 Tbaud bit slot of $\sim 785 \mathrm{fs}$, resulting in some pulse tail overlap. Finally, note that the BPFs in the receiver differ between the measurements on 640 and 1280 Gbaud, causing the difference in reference sensitivity. At 640 Gbaud, narrow $0.3 \mathrm{~nm}$ and $0.9 \mathrm{~nm}$ BPFs are used to achieve the best reference sensitivity, but at the cost of a limit in the amount of received power. At $1.28 \mathrm{Tbaud}$, a higher received power is required to reach a $\mathrm{BER}<10^{-9}$, and $1 \mathrm{~nm}$ and $5 \mathrm{~nm}$ BPFs are therefore selected.

To conclude on this section, we have shown that it is indeed possible to achieve several Tbit/s on a single laser source and that Tbaud symbol rates are appropriate for this usage.

\section{Network Applications}

At $640 \mathrm{Gbit} / \mathrm{s}$, several essential network functionalities have already been demonstrated. This goes for add/drop multiplexing $[19,20,29]$, wavelength conversion $[17,18,30,31]$,
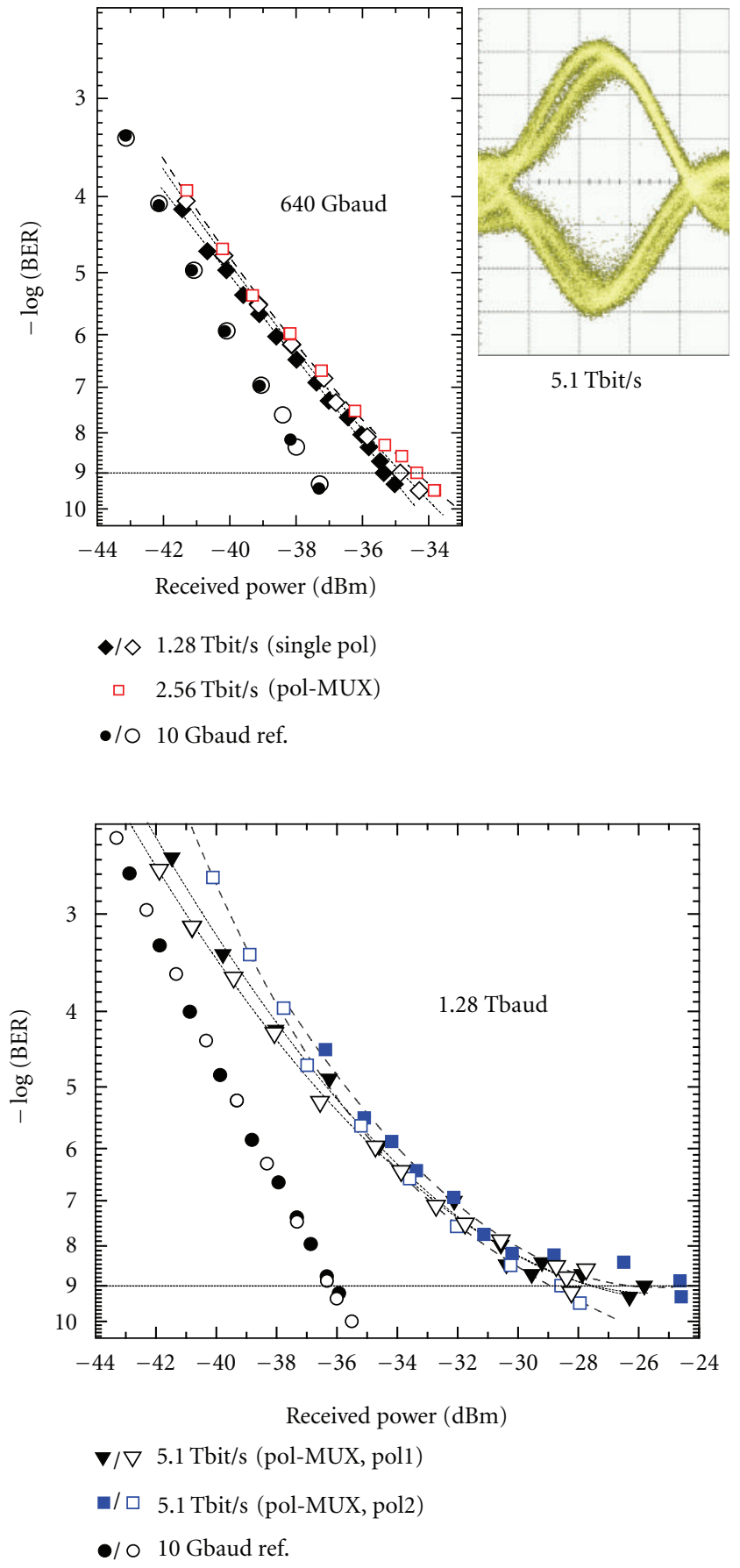

Figure 15: 5.1 Tbit/s demultiplexing and demodulation. 


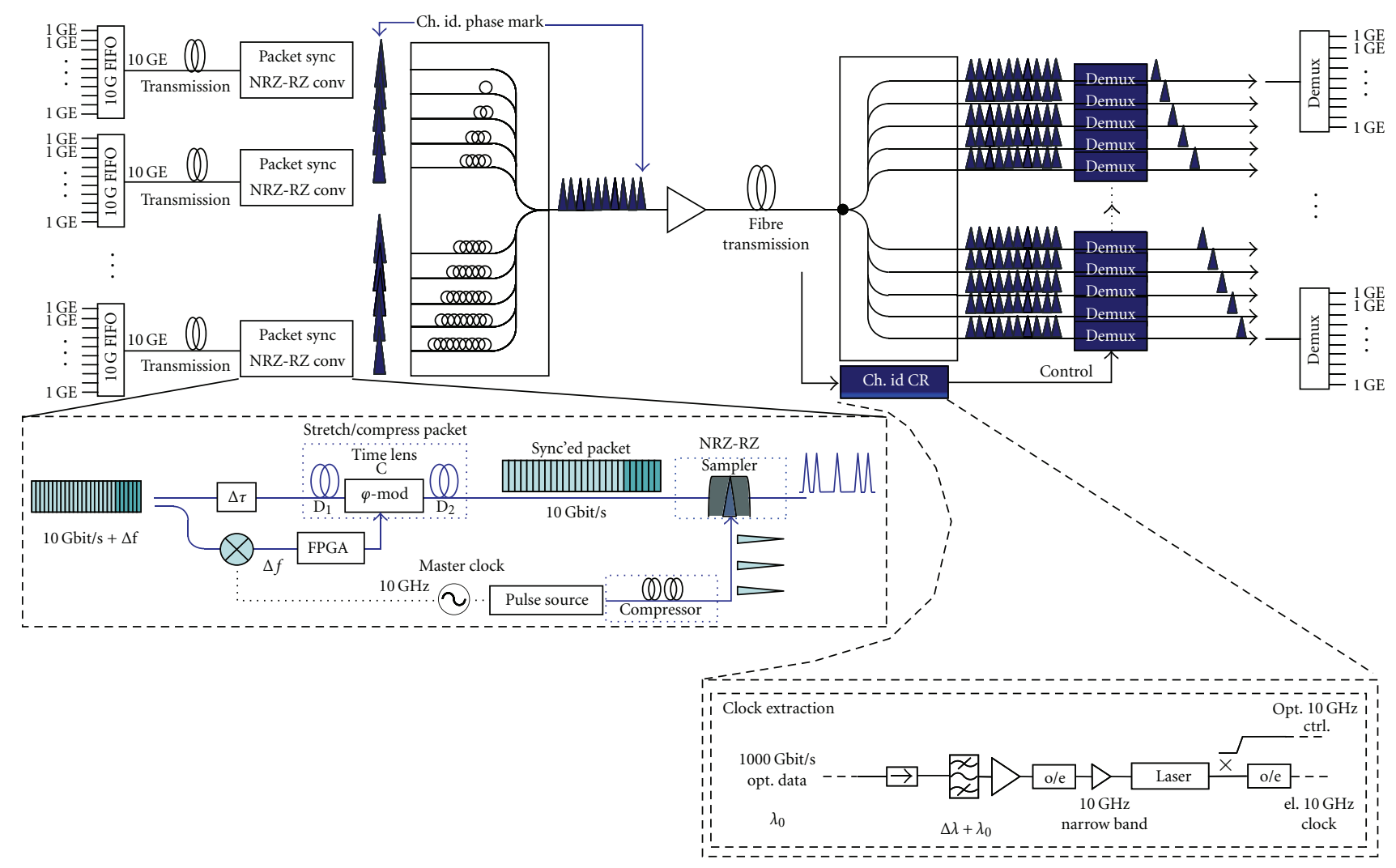

FIGURE 16: Suggested Ethernet compatible optical TDM system. Each 10 GE packet is synchronised to the local master clock via a time-lensbased sync unit, essentially stretching or compressing the data packet to fit the individual bits to the local rep rate. The synchronised bits in the packet are then individually converted to RZ pulses, for example, by optical sampling, allowing for subsequent time domain multiplexing, by interleaving the bits with those from other synchronised packets. Thus, each packet is ascribed its own time slot. Time slot $\mathrm{N}$ may also be marked with a channel ID, for example, by a slight phase modulation, allowing for easy channel identification and sub rate clock recovery at the receiver. The demultiplexing may take place in several ways and is here only conceptually shown as parallel demux-units for simplicity.

clock recovery using an SOA [32] and a PPLN [33], and full transmission including clock recovery and error-free demultiplexing $[32,33]$. To get full advantage of these highspeed functionalities, one would need to design new network scenarios or rethink the network. For instance, as suggested in Figure 16, it may be beneficial to create a high-speed bus to carry Ethernet data packets (frames) in optical TDM time slots, that is, multiplex Ethernet packets into timeslots by bit interleaving.

Ethernet is basically a TDM-based technology, and when considering the need for future Tbit/s Ethernet [5] and the Tbit/s capacity encountered in massive data centres, it makes sense to explore the potential of optical TDM in conjunction with Ethernet. Figure 16 shows an Ethernet compatible optical TDM scenario. The heart of this scheme is to use the optical time lens effect [34] derived from the space-time duality [35] to slightly stretch or compress the asynchronous Ethernet data packets to synchronize them to a local master clock. When synchronised they may be NRZ-RZ converted, for example, through optical sampling or pulse compression, and subsequently multiplexed together with other Ethernet packets or optical TDM channels.
In this scheme, each Ethernet packet would be assigned an OTDM time slot. The scheme has already been demonstrated in a proof-of-principle experiment reaching an aggregate bit rate of $50 \mathrm{Gbit} / \mathrm{s}$ [36] and recently $320 \mathrm{Gbit} / \mathrm{s}$ [37]. The results are errorrfree as shown in Figure 17. This scheme is scalable to Tbit/s.

As Ethernet packets are asynchronous, and optical TDM systems are very synchronous, it becomes important to synchronize the data packets to a local master clock. This can be carried out using the concept of a time lens $[34,35]$ by which the packet may be stretched or compressed to fit with the local clock frequency. Results on this are shown in Figure 17 where a $10 \mathrm{Gbit} / \mathrm{s}$ data packet is synchronised to four $10 \mathrm{Gbit} / \mathrm{s}$ optical TDM channels and then multiplexed together with these [36]. To prove the principle, subsequent demultiplexing was done and error-free performance confirmed. This principle is scalable to terabits per second.

Figure 18 shows results on another network building block, namely, that of channel identification combined with clock recovery. In this scheme, a small spectral feature is added to one optical TDM channel in the transmitter, and this is then simply filtered out in the receiver, allowing for 

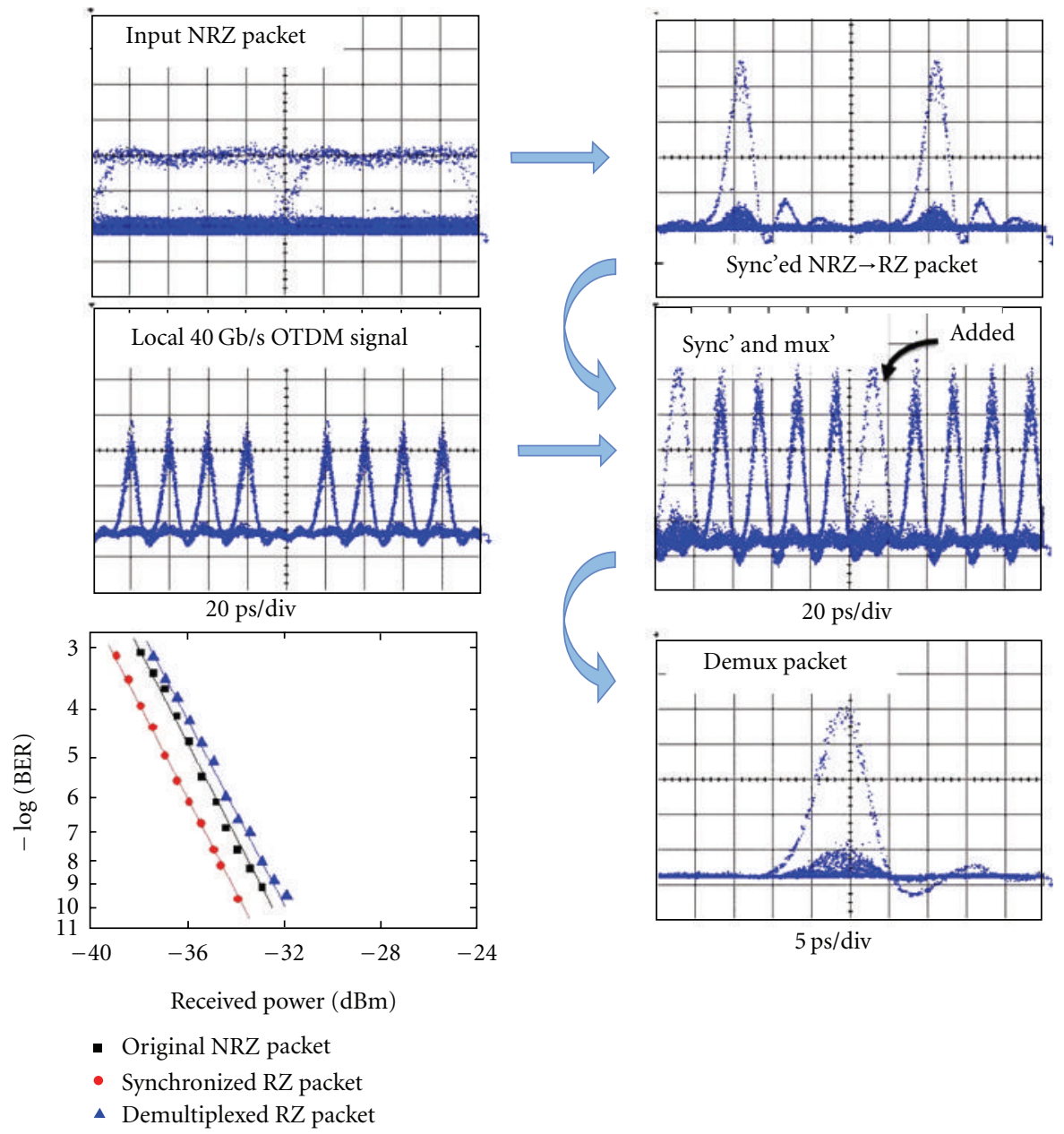

Figure 17: Time-lens-based data packet synchronisation and RZ conversion. A 12.000 bits long NRZ packet offset with $200 \mathrm{kHz}$ to the local clock is synchronised, RZ-converted, and multiplexed with a $40 \mathrm{Gbit} / \mathrm{s}$ OTDM signal. To prove the principle, demultiplexing with error-free BER performance is performed [19].

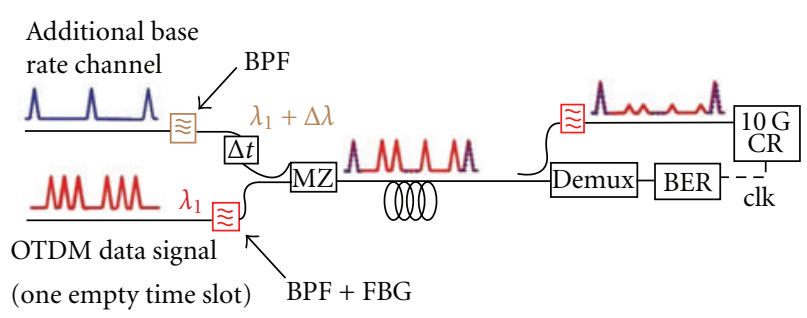

-After $80 \mathrm{~km}$ transmission and compensation

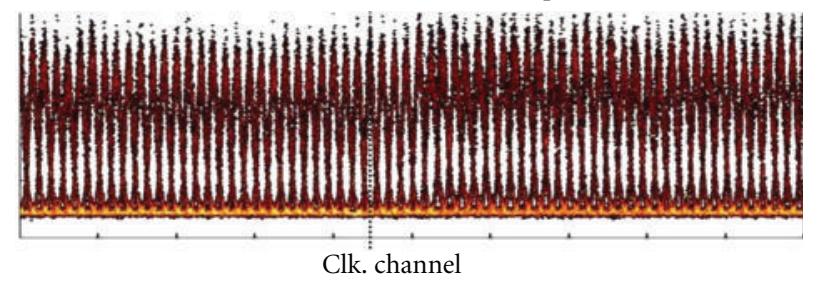

Figure 18: $650 \mathrm{Gbit} / \mathrm{s}$ channel identification and simultaneous clock recovery by adding a small spectral feature to one TDM channel [38]. easy identification of that particular channel. This scheme was demonstrated at $650 \mathrm{Gbit} / \mathrm{s}$, that is, where a marked channel was added to a $640 \mathrm{Gbit} / \mathrm{s}$ optical TDM signal [38]. Again, this scheme should be scalable to Tbit/s speeds. The added channel could stem from an Ethernet packet, and several spectral marks could be envisaged to allow for individual labeling of the TDM data packets.

Ultrafast data signals like Tbaud data require equally ultra-fast switches and are sensitive to temporal issues such as pulse widths and timing jitter. Therefore, timing jitter tolerant switching techniques are interesting. To this end, the OFT/time lens concept has again turned out to be very useful to create flat-top pulses [40] and compensate for dispersion [26], retiming [34], packet compression [41], and packet synchronisation [36]. Several pulse shaping schemes have been demonstrated for sub-ps flat-top pulse generation, such as the optical differentiation technique [42], and the MachZehnder delay technique [43], and used for timing-tolerant as well as polarization-independent switching [44]. 


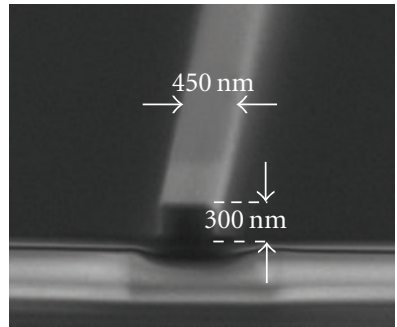

(a)

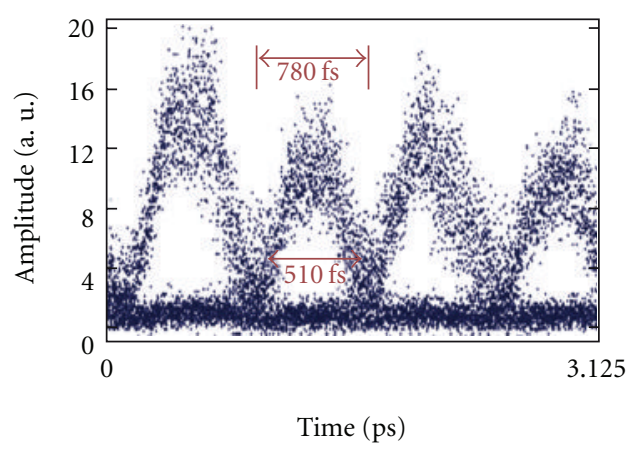

(b)

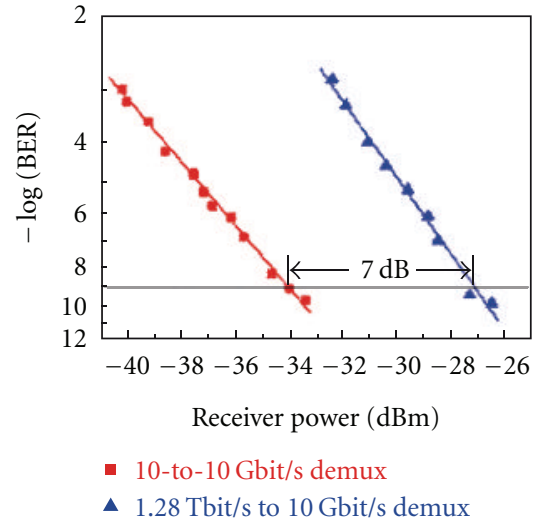

(c)

FIGURE 19: Ultra-fast silicon photonics. Using four-wave mixing in a silicon nanowire (a) is demonstrated to perform Tbit/s optical signal processing by sampling a $1.28 \mathrm{Tbit} / \mathrm{s}$ serial data signal (b) and error-free demultiplexing [39].

\section{Switching Materials}

Most Tbaud experiments have been carried out using a highly non-linear-fibre-(HNLF) based switch, for example, a non-linear optical loop mirror (NOLM). HNLF has superior efficiency and is convenient to use but is not compact and cannot be integrated onto a chip. Very recently, it was demonstrated that compact devices can be used for Tbit/s switching, for example, chalcogenide (ChG) waveguides and silicon nanowires [24, 39]. These results, together with $640 \mathrm{Gbit} / \mathrm{s}$ semiconductor-optical-amplifier(SOA-) based demultiplexers [45, 46], show great promise for making compact multifunctional optical chips with ultrahigh-speed potential. Figure 19 shows recent results on the use of a silicon nanowire for optical signal processing of a 1.28 Tbit/s serial data signal. The Si-nanowire is used as a nonlinear waveguide for four wave mixing (FWM) between a control and a data pulse in order to perform all-optical sampling (Figure 19(b)). These measured eye diagrams constitute the shortest sampled data pulses reported so far. The sampled data pulse width is $510 \mathrm{fs}$, and the distance between data pulses is $785 \mathrm{fs}$. The Si-nanowire is also used for demultiplexing the $1.28 \mathrm{Tbit} / \mathrm{s}$ data signal, and as seen in Figure 19(c), error-free performance is achieved. This is the highest signal processing speed reported to date using silicon—and indeed pure silicon.

\section{Conclusion}

We have described the generation and use of 1.28 Tbaud serial symbol rates for a $1.28 \mathrm{Tbit} / \mathrm{s}$ OOK data experimental demonstration and a $5.1 \mathrm{Tbit} / \mathrm{s}$ DQPSK pol-MUX data experimental demonstration. We have also described that there are several technology platforms that can potentially deal with such high symbol rates, with a number of these, including compact alternatives, already demonstrated at 640 Gbit/s (640 Gbaud). We have shown that Tbit/s optical TDM is feasible even for transmission. We have described efforts to embrace network scenarios and demonstrated data packet synchronisation for future Tbit/s Ethernet systems, for example, in Data Centres. Finally we have touched upon some emerging techniques which could enable more resilient and efficient switching, such as the time lens concept and silicon nanowires. This means that Tbit/s serial optical data may be a feasible path to accommodate for the future need for high-capacity communication systems.

\section{Acknowledgments}

This work is partly funded by the European-ResearchCouncil-(ERC-) independent researcher starter grant project SOCRATES and the Danish Research Council projects NANO-COM and NOSFERATU, and the European Network of Excellence, Euro-Fos. OFS Fitel Denmark Aps is acknowledged for providing HNLF.

\section{References}

[1] B. Mikkelsen, C. Rasmussen, F. Liu, P. Mamyshev, and S. Dey, "40 Gbit/s based ULH transmission," in Proceedings of the 9th OptoElectronics and Communications Conference (OECC '04), July 2004, Paper 14C3-1.

[2] R. Driad, R. E. Makon, V. Hurm et al., "INP DHBT-based ICs for $100 \mathrm{Gbit} / \mathrm{s}$ data transmission," in the International Conference on Indium Phosphide and Related Materials (IPRM '08), May 2008.

[3] K. Hinton, G. Raskutti, P. M. Farrell, and R. S. Tucker, "Switching energy and device size limits on digital photonic signal processing technologies," IEEE Journal on Selected Topics in Quantum Electronics, vol. 14, no. 3, pp. 938-945, 2008.

[4] M. Nakazawa, T. Yamamoto, and K. R. Tamura, "1.28Tbit/s$70 \mathrm{~km}$ OTDM transmission using third- and fourth-order simultaneous dispersion compensation with a phase modulator," Electronics Letters, vol. 36, no. 24, pp. 2027-2029, 2000.

[5] B. Metcalfe, http://www.ofcnfoec.org/Home/Program/ Plenary-Session.aspx.

[6] E. B. Desurvire, "Capacity demand and technology challenges for lightwave systems in the next two decades," Journal of Lightwave Technology, vol. 24, no. 12, pp. 4697-4710, 2006.

[7] H. G. Weber, S. Ferber, M. Kroh et al., "Single channel $1.28 \mathrm{Tbit} / \mathrm{s}$ and $2.56 \mathrm{Tbit} / \mathrm{s}$ DQPSK transmission," Electronics Letters, vol. 42, no. 3, pp. 67-68, 2006. 
[8] C. Schmidt-Langhorst et al., "Generation and coherent timedivision demultiplexing of up to $5.1 \mathrm{~Tb} / \mathrm{s}$ single-channel 8PSK and 16-QAM signals," in Proceedings of the Conference on Optical Fiber Communication (OFC '09), 2009, paper PDPC6.

[9] C. Zhang et al., "Demodulation of $1.28 \mathrm{Tbit} / \mathrm{s}$ polarizationmultiplexed 16-QAM signals on a single carrier with digital coherent receiver," in Proceedings of the Conference on Optical Fiber Communication (OFC '09), 2009, paper OTuG3.

[10] Y. Ma et al., " $1 \mathrm{~Tb} / \mathrm{s}$ per channel coherent optical OFDM transmission with subwavelength bandwidth access," in Proceedings of the Conference on Optical Fiber Communication (OFC '09), 2009, PD paper PDPC1.

[11] R. Dischler et al., "Transmission of $1.2 \mathrm{Tbit} / \mathrm{s}$ continuous waveband PDM-OFDM-FDM signal with spectral efficiency of $3.3 \mathrm{bit} / \mathrm{s} / \mathrm{Hz}$ over $400 \mathrm{~km}$ of SSMF," in Proceedings of the Conference on Optical Fiber Communication (OFC '09), 2009, paper PDPC2.

[12] R. Slavík, F. Parmigiani, J. Kakande et al., "All-optical phase and amplitude regenerator for next-generation telecommunications systems," Nature Photonics, vol. 4, no. 10, pp. 690-695, 2010.

[13] H. C. Hansen Mulvad, L. K. Oxenløwe, M. Galili, A. T. Clausen, L. Grüner-Nielsen, and P. Jeppesen, "1.28Tbit/s single-polarisation serial OOK optical data generation and demultiplexing," Electronics Letters, vol. 45, no. 5, pp. 280-281, 2009.

[14] H. C. Hansen Mulvad, M. Galili, L. K. Oxenløwe et al., "Error-free $5.1 \mathrm{Tbit} / \mathrm{s}$ data on a single-wavelength channel using a 1.28 Tbaud symbol rate," in Proceedings of the 22nd Annual Meeting of the IEEE Photonics Society, Belek-Antalya, Turkey, October 2009.

[15] L. K. Oxenløwe, F. Gómez-Agis, C. Ware et al., “640-Gbit/s data transmission and clock recovery using an ultrafast periodically poled lithium niobate device," Journal of Lightwave Technology, vol. 27, no. 3, pp. 205-213, 2009.

[16] L. K. Oxenløwe, F. Gomez Agis, C. Ware et al., "640Gbit/s clock recovery using periodically poled lithium niobate," Electronics Letters, vol. 44, no. 5, pp. 370-372, 2008.

[17] M. Galili, L. K. Oxenløwe, H. C. H. Mulvad, A. T. Clausen, and P. Jeppesen, "Optical wavelength conversion by cross-phase modulation of data signals up to $640 \mathrm{~Gb} / \mathrm{s}$," IEEE Journal on Selected Topics in Quantum Electronics, vol. 14, no. 3, pp. 573-579, 2008.

[18] M. Galili, H. C. H. Mulvad, L. Grüner-Nielsen et al., " $640 \mathrm{Gbit} / \mathrm{s}$ optical wavelength conversion using FWM in a polarisation maintaining HNLF," in the 34th European Conference on Optical Communication (ECOC '08), September 2008.

[19] H. C. Hansen Mulvad et al., "640 Gbit/s optical time-division add-drop multiplexing in a non-linear optical loop mirror," in IEEE Lasers and Electro-Optics Society Winter Topical Meeting, Innsbruck, Austria, January 2009, Paper MC4.4.

[20] H. C. H. Mulvad, M. Galili, L. Grüner-Nielsen, L. K. Oxenløwe, A. T. Clausen, and P. Jeppesen, “640 Gbit/s time-division add-drop multiplexing using a non-linear polarisationrotating fibre loop," in the 34th European Conference on Optical Communication (ECOC '08), September 2008.

[21] S. Ashihara, T. Shimura, K. Kuroda et al., "Optical pulse compression using cascaded quadratic nonlinearities in periodically poled lithium niobate," Applied Physics Letters, vol. 84, no. 7, pp. 1055-1057, 2004.

[22] M. Galili, J. Xu, H. C. H. Mulvad et al., "Breakthrough switching speed with an all-optical chalcogenide glass chip: 640 Gbit/s demultiplexing," Optics Express, vol. 17, no. 4, pp. 2182-2187, 2009.
[23] M. Pelusi, F. Luan, T. D. Vo et al., "Photonic-chip-based radiofrequency spectrum analyser with terahertz bandwidth," Nature Photonics, vol. 3, no. 3, pp. 139-143, 2009.

[24] T. D. Vo, H. Hu, M. Galili et al., "Photonic chip based 1.28 Tbaud transmitter optimization and receiver OTDM demultiplexing," in Proceedings of the Conference on Optical Fiber Communication (OFC'10), 2010, paper PDPC5.

[25] H. Hu, M. Galili, L. K. Oxenløwe et al., "Error-free transmission of serial 1.28 Tbaud RZ-DPSK signal," in the European Conference on Optical Communication (ECOC '10), Turin, Italy, September 2010, Paper P4.18.

[26] M. Nakazawa, T. Hirooka, F. Futami, and S. Watanabe, "Ideal distortion-free transmission using optical Fourier transformation and Fourier transform-limited optical pulses," IEEE Photonics Technology Letters, vol. 16, no. 4, pp. 1059-1061, 2004.

[27] Y. Paquot et al., "Automatic higher-order dispersion measurement and compensation of a 1.28 Tbaud signal," in Proceedings of the Conference on Lasers and Electro-Optics (CLEO '11), 2011, paper CFP3.

[28] M. Akbulut, A. M. Weiner, and P. J. Miller, "Wideband allorder polarization mode dispersion compensation via pulse shaping," Optics Letters, vol. 30, no. 20, pp. 2691-2693, 2005.

[29] H. C. Hansen Mulvad, L. K. Oxenløwe, A. T. Clausen, M. Galili, L. Grüner-Nielsen, and P. Jeppesen, "Error-free 320 $\mathrm{Gb} / \mathrm{s}$ simultaneous add-drop multiplexing," in Proceedings of the Conference on Optical Fiber Communication (OFC '07), Anaheim, Calif, USA, March 2007, Paper OTuI.

[30] H. Sotobayashi, W. Chujo, and T. Ozeki, "Inter-wavelengthband conversions and demultiplexings of $640 \mathrm{Gbit} / \mathrm{s}$ OTDM signals," in Proceedings of the Conference on Optical Fiber Communication (OFC'02), pp. 261-262, 2002.

[31] H. Hu, E. Palushani, M. Galili et al., "1.28 Tb/s wavelength conversion for polarisation multiplexed RZ-DPSK signals," in Proceedings of the Conference on Optical Fiber Communication (OFC '10), San Diego, Calif, USA, March 2010, Paper OWP1.

[32] E. Tangdiongga et al., "SOA-based clock recovery and demultiplexing in a lab trial of 640- Gb/s OTDM transmission over 50-km Fibre Link," in the 33rd European Conference and Exhibition of Optical Communication (ECOC '07), 2007, PD 1.2.

[33] L. K. Oxenløwe, F. Gomez Agis, C. Ware et al., "640 Gbit/s data transmission and clock recovery using an ultra-fast periodically poled lithium niobate device," in Proceedings of the Conference on Optical Fiber Communication (OFC '08), San Diego, Calif, USA, February 2008, PDP22.

[34] L. F. Mollenauer and C. Xu, "Time-lens timing-jitter compensator in ultra-long haul DWDM dispersion managed soliton transmissions," in the Conference on Lasers and Electro-Optics (CLEO '02), pp. CPDB11-CPDB13, May 2002.

[35] Brian H. Kolner, "Space-time duality and the theory of temporal imaging," IEEE Journal of Quantum Electronics, vol. 30, no. 8, pp. 1951-1963, 1994.

[36] H. Hu, E. Palushani, J. L. Areal et al., "Optical frame synchronizer for $10 \mathrm{G}$ Ethernet packets aiming at $1 \mathrm{~Tb} / \mathrm{s}$ OTDM Ethernet," in Proceedings of the Conference on Optical Fiber Communication, Collocated National Fiber Optic Engineers Conference (OFC/NFOEC'10), 2010.

[37] J. L. Areal, H. Hu, and E. Palushani, "Synchronization and NRZ-to-RZ conversion of $10 \mathrm{Gbit} / \mathrm{s}$ Ethernet-like data packets and subsequent optical TDM multiplexing to $330 \mathrm{Gbit} / \mathrm{s}$," in Proceedings of the Conference on Optical Fiber Communication (OFC'11), 2011.

[38] M. Galili, H. C. Hansen Mulvad, H. Hu et al., “650 Gbit/s OTDM transmission over $80 \mathrm{~km}$ SSMF incorporating clock 
recovery, channel identification and demultiplexing in a Polarisation insensitive receiver," in Proceedings of the Conference on Optical Fiber Communication, Collocated National Fiber Optic Engineers Conference (OFC/NFOEC'10), 2010, OWO3.

[39] H. Ji, H. Hu, M. Galili et al., "Optical waveform sampling and error-free demultiplexing of $1.28 \mathrm{Tbit} / \mathrm{s}$ serial data in a silicon nanowire," in the Conference on Optical Fiber Communication, Collocated National Fiber Optic Engineers Conference (OFC/NFOEC'10), 2010, PDPC7.

[40] E. Palushani, L. K. Oxenløwe, M. Galili, H. C. H. Mulvad, A. T. Clausen, and P. Jeppesen, "Flat-top pulse generation by the optical fourier transform technique for ultrahigh speed signal processing," IEEE Journal of Quantum Electronics, vol. 45, no. 11, pp. 1317-1324, 2009.

[41] M. A. Foster et al., "Generation of $270 \mathrm{~Gb} / \mathrm{s} \mathrm{NRZ} \mathrm{data} \mathrm{packets}$ from a $10-\mathrm{Gb} / \mathrm{s}$ signal using a temporal telescopic system," in Proceedings of the Conference on Optical Fiber Communication (OFC '09), 2009, OWS4.

[42] L. K. Oxenløwe, R. Slavík, M. Galili et al., “640 Gb/s timing jitter-tolerant data processing using a long-period fibergrating-based flat-top pulse shaper," IEEE Journal on Selected Topics in Quantum Electronics, vol. 14, no. 3, pp. 566-572, 2008.

[43] E. Palushani, H. Hu, L. K. Oxenløwe et al., "640 Gb/s timing tolerant demultiplexing using a cascaded long-period fiber grating pulse shaper," in the 35th European Conference on Optical Communication (ECOC'09), 2009.

[44] H. C. H. Mulvad, M. Galili, L. K. Oxenløwe, A. T. Clausen, L. Grüner-Nielsen, and P. Jeppesen, "Polarization-independent high-speed switching in a standard non-linear optical loop mirror," in Proceedings of the Conference on Optical Fiber Communication/National Fiber Optic Engineers Conference (OFC/NFOEC'08), 2008.

[45] E. Tangdiongga et al., "SOA-based clock recovery and demultiplexing in a lab trial of 640- Gb/s OTDM transmission over 50km fibre link," in the 33rd European Conference and Exhibition of Optical Communication (ECOC '07), 2007, PD 1.2.

[46] T. Hirooka, M. Okazaki, T. Hirano, P. Guan, M. Nakazawa, and S. Nakamura, "All-optical demultiplexing of $640 \mathrm{Gbit} / \mathrm{s}$ OTDM-DPSK signal using a semiconductor SMZ switch," in the 35th European Conference on Optical Communication (ECOC 09), 2009, paper 4.3.2. 

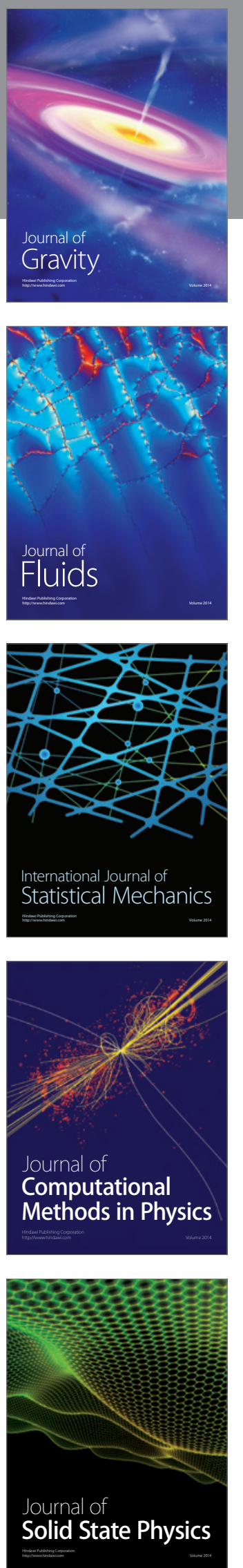

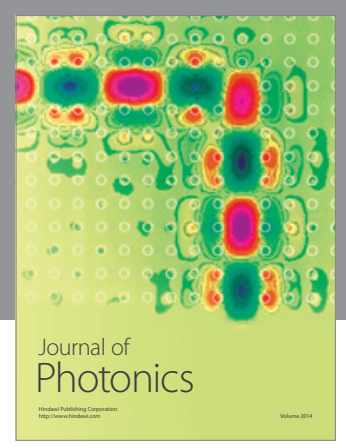

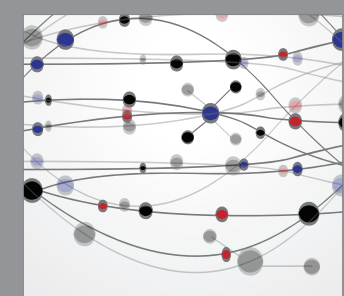

The Scientific World Journal
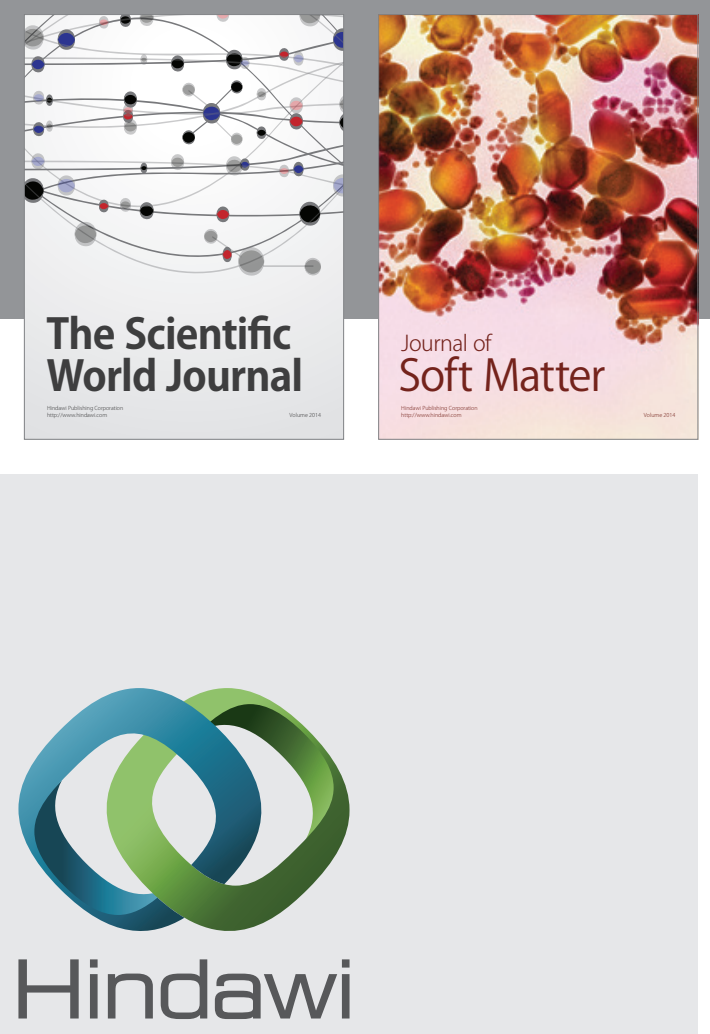

Submit your manuscripts at

http://www.hindawi.com
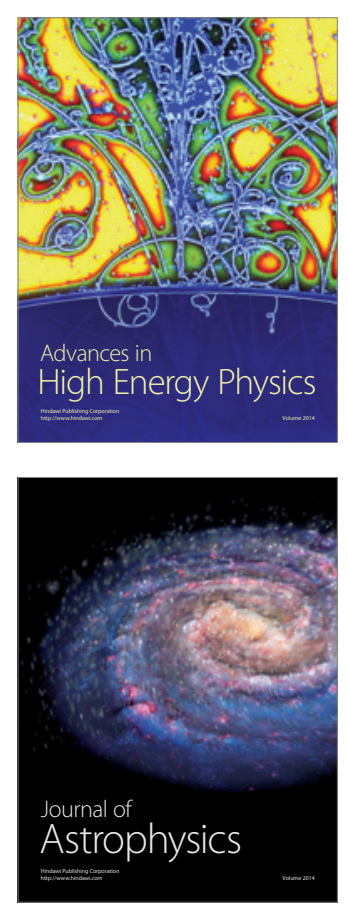
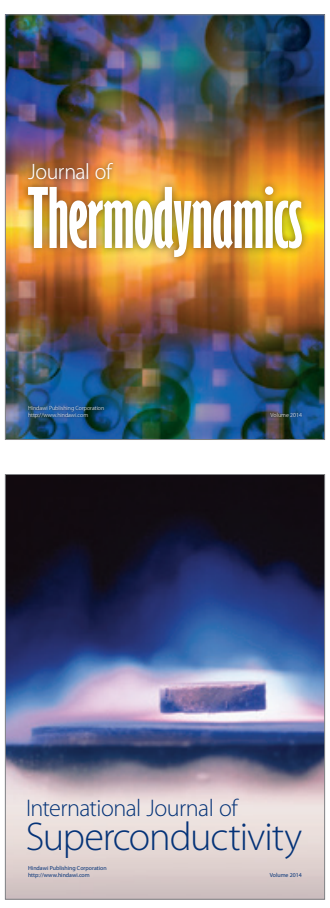
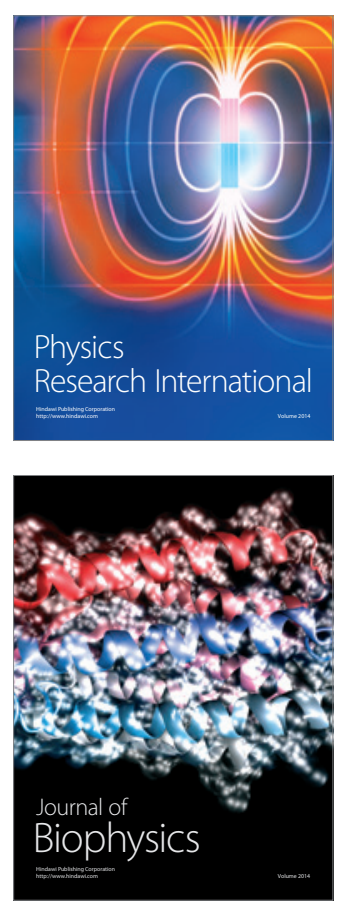
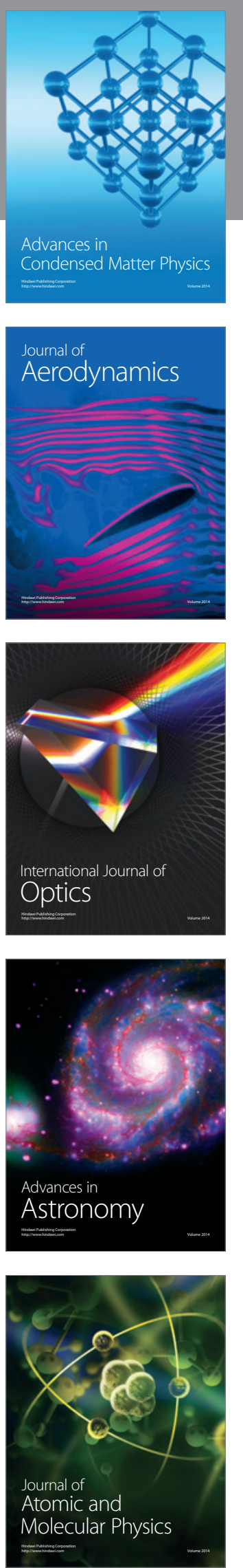